\title{
Peripheral microRNA alteration and pathway signaling after mild traumatic brain injury
}

\author{
Katarina Matyasova $^{1, \star}$, Nikoleta Csicsatkova $^{1, \star}$, Peter Filipcik ${ }^{1,2}$, Igor Jurisica ${ }^{1,3,4,5}$ \\ and Martin Cente ${ }^{1,2}$ (D) \\ ${ }^{1}$ Institute of Neuroimmunology, Slovak Academy of Sciences, Bratislava, Slovakia \\ ${ }^{2}$ Axon Neuroscience R\&D Services SE, Bratislava, Slovakia \\ ${ }^{3}$ Osteoarthritis Research Program, Division of Orthopedic Surgery, Schroeder Arthritis Institute, University Health Network, \\ Toronto, Ontario, Canada \\ ${ }^{4}$ Data Science Discovery Centre for Chronic Diseases, Krembil Research Institute, University Health Network, Toronto, \\ Ontario, Canada \\ ${ }^{5}$ Departments of Medical Biophysics and Computer Science, University of Toronto, Toronto, Ontario, Canada
}

\begin{abstract}
Discovering novel diagnostic biomarkers and signatures for traumatic brain injury (TBI) represents a major challenge in the brain trauma research. Detailed analysis of post-concussive molecular pathways based on experimental data could provide a new insight into the pathophysiological sequelae and mapping of recovery mechanisms involved in TBI. MicroRNAs (miRNAs) detectable in peripheral body fluids after TBI are promising carriers of this missing knowledge. In order to define the signature of peripheral miRNAs signaling associated with mild TBI (mTBI), we performed a comprehensive meta-analysis of miRNA profiles in mTBI patients using multiple curated pathway databases. Using a bioinformatic pipeline with integrated data analysis we identified a set of genes that are connected to deregulated circulating miRNAs following the mTBI. Identified genes belong to specific pathways of MAPK, TGF- $\beta$, WNT, TLR2/4, PI3K/AKT, insulin, and growth factor signaling. Since the enriched pathways markedly overlap among the various biological fluids, signaling associated with mTBI that is concomitantly reflected in serum, plasma and saliva is robust and unique. Furthermore, we identified a network of 33 validated interacting proteins and their regulatory miRNAs that link the post-mTBI signaling in peripheral fluids with neurodegenerationassociated interaction pathways. Presented data provide a comprehensive insight into molecular events following $\mathrm{mTBI}$, and the top predicted genes represent a group of novel candidate targets to be validated in connection with mTBI.
\end{abstract}

Key words: Mild traumatic brain injury - TBI - miRNA - Signaling pathways - Metaanalysis

Electronic supplementary material. The online version of this article (doi: 10.4149/gpb_2021038) contains Supplementary material.

* These authors contributed equally to this work.

Correspondence to: Martin Cente, Institute of Neuroimmunology, Slovak Academy of Sciences, Dubravska cesta 9, 84510 Bratislava, Slovakia

E-mail: martin.cente@savba.sk
Igor Jurisica, Data Science Discovery Centre for Chronic Diseases, Krembil Research Institute, University Health Network, 60 Leonard Avenue, 5KD-407, Toronto, Ontario, Canada M5T 0S8

E-mail: juris@ai.utoronto.ca

(c) The Authors 2021. This is an open access article under the terms of the Creative Commons Attribution-NonCommercial 4.0 International License (https://creativecommons.org/licenses/by-nc/4.0/), which permits non-commercial use, distribution, and reproduction in any medium, provided the original work is properly cited. 


\section{Introduction}

Traumatic brain injury (TBI) is defined by a disruption of normal brain function as a reaction to external physical force (Menon et al. 2010). The estimated incidence of TBI per 100000 people represents 948 cases in Asia, 1012 cases in Europe and the numbers are even higher (1299 cases) in North America (Dewan et al. 2019). Patients with mild TBI (mTBI) represent majority of the hospital-treated adult head injuries (70-90\%); however, the overall numbers are likely underestimated since many mild head injuries remain unreported and thus undiagnosed (Cassidy et al. 2004; McCrea et al. 2017). Evaluation by the Glasgow coma scale (GCS) is a widely used diagnostic approach to determine the severity of TBI by observing patient's motor, eye, and verbal responses (Teasdale and Jennett 1976). The score of 13-15 refers to mTBI, 9-12 points to moderate TBI, and less than 8 to severe TBI (Iankova 2006). In addition to GCS, computed tomography (CT) and magnetic resonance imaging (MRI) are the most available and used neuroimaging techniques in the clinical management of brain injury (Shetty et al. 2016). However, the CT and MRI conclude very often normal findings reporting no abnormalities in mTBI patients (Iverson et al. 2000; Wintermark et al. 2015). Typically, most patients after mTBI or sport-related concussion fully recover after 7-10 days, although this period can be prolonged in children and adolescents (McCrory et al. 2005).

Recent research indicates that TBI may increase the risk for the development of neurodegenerative disorders evolved due to longitudinal sequelae of concussion or repetitive sub-concussive head impacts (Bailes et al. 2013; Manley et al. 2017; Alosco et al. 2018). For instance, single moderate, single severe TBI or even repeated mild head injuries are associated with the development of chronic traumatic encephalopathy (CTE) as it was reported in professional contact sport athletes (Omalu et al. 2005; McKee et al. 2009; Smith et al. 2013; Omalu and Hammers 2021). Moreover, the risk of Alzheimer's disease has been reported as 1.5 times higher following head trauma (Li et al. 2017). Similarly, the increased risk of Parkinson's disease has been described in military personnel suffering various severities of TBI (Gardner et al. 2018). Additional to the neurodegeneration, head trauma has a significant impact on mental health of TBI individuals as well. Patients with TBI frequently suffer from sleep disturbance (Gilbert et al. 2015) and psychiatric disorders including depression (Jorge et al. 1993), aggression (Gallant et al. 2018) or posttraumatic stress disorder (Bryant and Harvey 1998).

Although it is not possible to accurately predict the consequences of TBI, peripheral biomarkers could represent a valuable diagnostic and prognostic asset. In particular, the group of peripheral microRNAs (miRNAs) has been shown to be associated with mTBI (Redell et al. 2010; Hicks et al. 2020b) and various neurodegenerative disorders (Sheinerman et al. 2017; Siedlecki-Wullich et al. 2019; Uwatoko et al. 2019). The diagnostic potential of miRNAs originates from their general abundance, resistance against degradation, stability in different biofluids (Keller et al. 2017) and sensitive methods of detection. Furthermore, their regulatory role at post-transcriptional level enables identification of specific disease patterns and molecular signaling pathways associated with pathophysiological processes known to be involved in neurodegenerative diseases.

In the present study, we present a meta-analysis of circulating miRNA profiles in patients experiencing mTBI. Using an integrated bioinformatic pipeline we aimed to identify the molecular signature of candidate target genes, associated signaling pathways and involved protein interactions in the mTBI cascade. Special emphasis was placed on clarifying the link between post-concussive signaling and induction of neurodegeneration-associated interaction pathways. This approach helps to improve our understanding of the molecular events present in the brain and eventually mirrored in peripheral fluids during early post-traumatic period and to discover the novel candidate markers/targets associated with mTBI.

\section{Methods}

\section{Search strategy, selection criteria and data extraction}

A systematic search of relevant studies describing the altered miRNA expression levels in human peripheral biofluids of patients diagnosed with mTBI was performed in the PubMed database using the following query: ("traumatic brain injury" [Title/Abstract] OR "traumatic brain injuries" [Title/Abstract] OR “TBI"[Title/Abstract] OR "head trauma"[Title/Abstract] OR "head traumas"[Title/Abstract] OR "concussion" [Title/Abstract] OR "concussions"[Title/ Abstract] OR "head impact"[Title/Abstract] OR "head impacts"[Title/Abstract]) AND ("microRNA"[Title/Abstract] OR "microRNAs"[Title/Abstract] OR "miRNA" [Title/ Abstract] OR "miRNAs"[Title/Abstract] OR "mirna biomarker"[Title/Abstract] OR "mirna biomarkers"[Title/ Abstract]). In total, 220 articles published before December 31,2020 , were identified.

The inclusion criteria for the articles were as follows: (1) original research, (2) mTBI patients clinically diagnosed according to GCS $\geq 13$, (3) miRNA expression study in human peripheral biofluids, (4) acute post-TBI time $<15$ days. First, the titles and abstracts of searched articles were screened, followed by review of full texts to assess the data eligibility. Articles were excluded based on the following criteria: (1) not TBI or miRNA-related articles, (2) reviews, 
meta-analyses, observational studies, or reports, (3) tissue or animal and cell experiments, (4) studies not published in English. Second, after full-text evaluation, articles were excluded if the severity of TBI was not determined with the GCS at all or did not meet a criterion of GCS score 13-15 that defines mTBI (Iankova 2006). Additionally, the articles with unclear regulation of miRNA (data constraints) or mixed mild to severe TBI cohorts, as well as those describing the longer post injury time ( $>15$ days after the injury) or studies without a non-TBI cohort as a control group, were excluded (Fig. 1). The search strategy resulted in 8 articles included in the meta-analysis (Redell et al. 2010; Yang et al. 2016; Di Pietro et al. 2017; Qin et al. 2018; Sun et al. 2018; Yan et al. 2019; Hicks et al. 2020b; Tas et al. 2020).

From the final set of selected studies, the following data of interest were extracted: study details (authors, publication year), list of deregulated miRNAs, type of biofluid as a sample source, methodology used to detect miRNAs levels including the normalisation of the data, information about patients and control cohorts, GCS score of the patients, time of sample collection after the injury, $p$-value, and regulation status of miRNAs (upregulated or downregulated). Following the statistical method in the articles, a $p$-value $<0.05$ was considered significant while also taking to account the predictive models for miRNAs as mTBI diagnostic candidates. Curated source miRNA data including cohort details are summarized in Supplementary Material (Supplement 1).

\section{miRNA:target identification}

Prediction of gene targets for differentially expressed miRNAs was performed using the mirDIP: microRNA Data Integration Portal (http://ophid.utoronto.ca/mirDIP) version 4.1.11.1 (Database version 4.1.0.3.), which integrates 30 different algorithms (Tokar et al. 2018). Identification of miRNA putative targets involved all 30 databases at very high confidence level (39 miRNAs), except for the $4 \mathrm{miR}$ NAs where a high score class filter was employed to query the predictions. The miR-12136 was the only miRNA that is not included in the mirDIP database and thus did not yield putative targets in any of the used resources. All raw data and search results are included in Supplement 2.

\section{Comprehensive pathway enrichment}

Putative target genes defined by mirDIP were used to identify significantly enriched pathways performing a pathway enrichment analysis via pathDIP: pathway Data Integration Portal http://ophid.utoronto.ca/pathDIP version 4.0.21.2 (Database version 4.0.7.0) (Rahmati et al. 2020). We have used all 22 pathway sources and only known literature curated (core) pathway memberships considering $q$-value $<0.05$ (false discovery rate: Benjamini-Hochberg method). Significantly enriched pathways were then processed to identify enriched terms in the pathway titles (word enrichment analysis; Supplement 3). To visualize
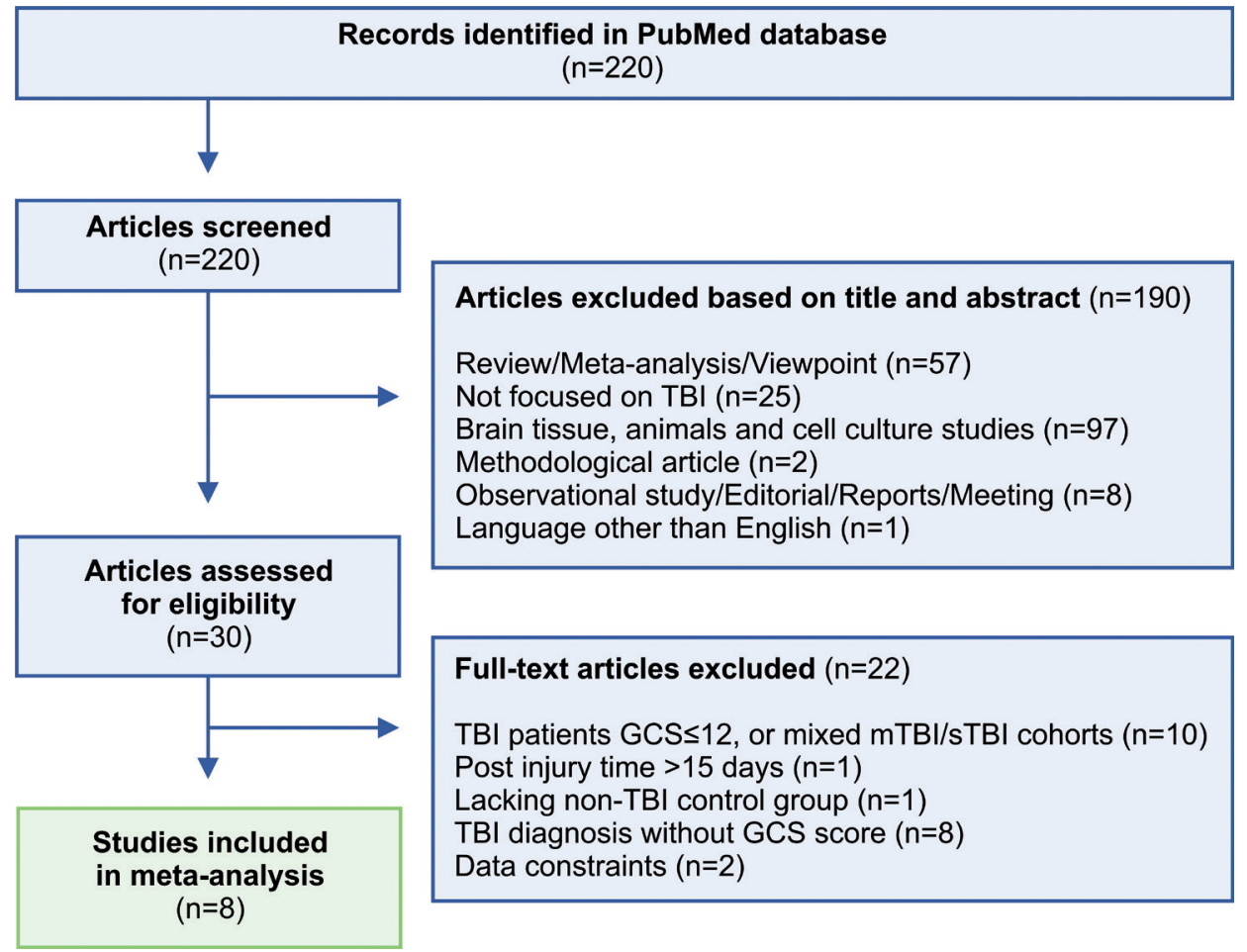

Articles excluded based on title and abstract $(n=190)$

Review/Meta-analysis/Viewpoint $(n=57)$

Not focused on TBI $(n=25)$

Brain tissue, animals and cell culture studies $(n=97)$

Methodological article $(n=2)$

Observational study/Editorial/Reports/Meeting $(n=8)$

Language other than English $(n=1)$

\section{Full-text articles excluded $(n=22)$}

TBI patients GCS $\leq 12$, or mixed mTBI/sTBI cohorts $(n=10)$

Post injury time $>15$ days $(n=1)$

Lacking non-TBI control group $(n=1)$

TBI diagnosis without GCS score $(n=8)$

Data constraints $(n=2)$
Figure 1. Flowchart of the metaanalysis selection criteria. 
both common and unique terms we used NAViGaTOR ver. 3.0.11, highlighted terms of significantly enriched pathways (blue, purple and black refers to low-to-higher q-value) and produced the SVG file as output. The SVG file was post-processed in CorelDRAW X7 version 17.1.0.572 to its final form (Fig. 4B).

\section{Protein-protein interactions}

Identified gene targets unique for particular biofluid (Supplement 2) were used to query Integrated Interactions Database (IID) (http://ophid.utoronto.ca/iid) version 2018-11 (Kotlyar et al. 2019) to retrieve direct physical protein interactions among them. Using DisGeNet (Pinero et al. 2017), edges were annotated with relevance to neurodegenerative disease, nervous system disease, tauopathy and Alzheimer's disease (data integrated in IID). NAViGaTOR was then used to visualize and analyse the resulting network. To identify the most important proteins within the network, we computed centrality and node degree. Closeness centrality provides ranking for each node based on the average length of any breadth-first search path. The most central proteins (and those with degree $>20$ ) were selected. To reduce network complexity, other nodes and edges were removed, resulting in the final network in Figure 5 (Supplement 4).

\section{Network analysis and visualization}

NAViGaTOR version 3.0.11 (Brown et al. 2009) was used to visualize and annotate miRNA:gene network and physical protein interaction network. Final graphs were exported in SVG format, and completed in CorelDRAW X7 version 17.1.0.572 to produce the final images with legends.

\section{Results}

To identify signaling pathways associated with mTBI, we analysed the differentially expressed circulating miRNAs in mTBI with integrative bioinformatic tools. The analytic pipeline combined the comprehensive miRNA:gene target prediction (mirDIP), pathway enrichment analysis (pathDIP) and final integration with physical protein-protein interactions (IID) (Fig. 2A).

Following the selection criteria, the data for bioinformatic evaluation were extracted from 220 searched articles resulting in 8 studies focusing on altered miRNA levels in peripheral biofluids of subjects with mTBI. For a more detailed analysis, we separately examined the deregulated miRNAs based on their origin using three biofluid sources, i.e., serum, plasma, and saliva. In total, data for 12 different miRNAs were col-
A
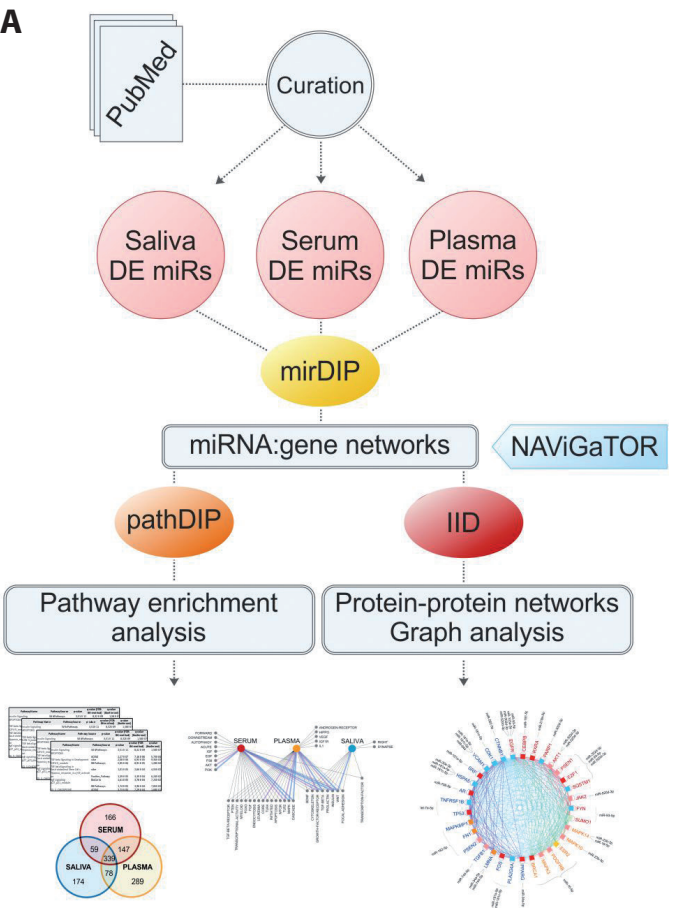

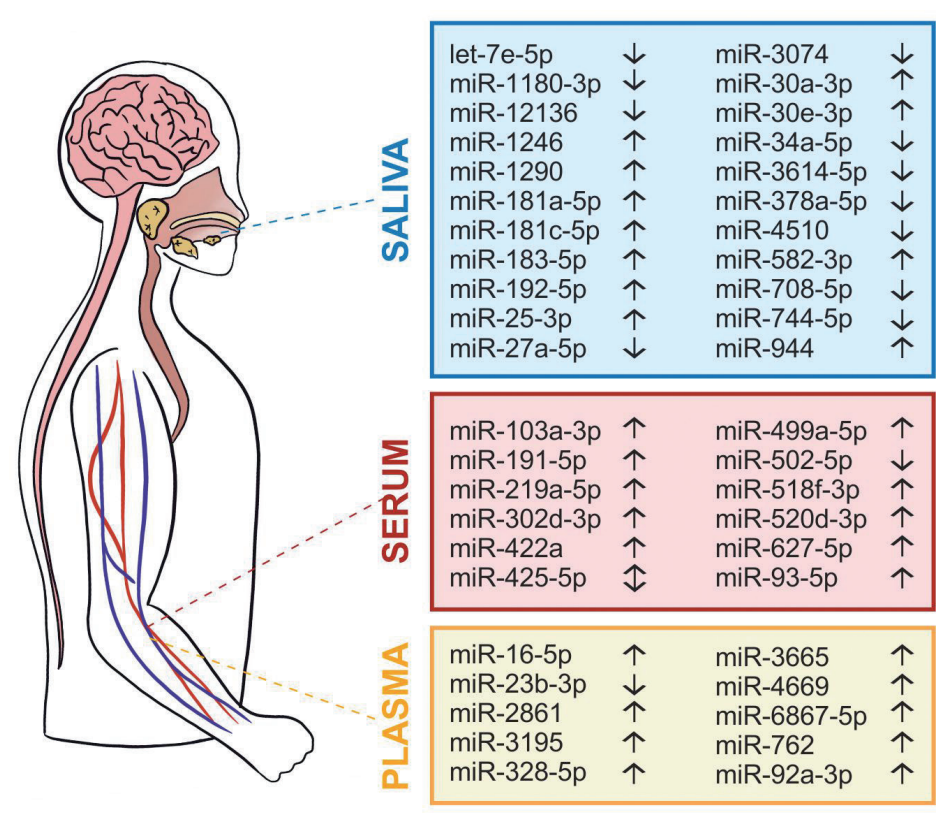

Figure 2. Design of the study. Pipeline of the bioinformatic analysis (A). Overview of the differentially expressed (DE) circulating miRNAs following mild TBI evaluated in the study (B). Arrows in the panel B represent direction of deregulation in particular biofluid, as reported in the original studies. mirDIP, microRNA Data Integration Portal; pathDIP, pathway Data Integration Portal; IID, Integrated Interactions Database. 
Table 1. Key deregulated circulating miRNAs involved in the peripheral signaling after mild traumatic brain injury (mTBI)

\begin{tabular}{|c|c|c|c|c|}
\hline miRNA & Sequence $\left(5^{\prime}-3^{\prime}\right)$ & Regulation & Biofluid & Number of targeted genes \\
\hline hsa-miR-103a-3p & AGCAGCAUUGUACAGGGCUAUGA & $\uparrow$ & \multirow{4}{*}{ Serum } & 2087 \\
\hline hsa-miR-302d-3p & UAAGUGCUUCCAUGUUUGAGUGU & $\uparrow$ & & 1673 \\
\hline hsa-miR-520d-3p & AAAGUGCUUCUCUUUGGUGGGU & $\uparrow$ & & 1566 \\
\hline hsa-miR-93-5p & CAAAGUGCUGUUCGUGCAGGUAG & $\uparrow$ & & 2540 \\
\hline hsa-miR-16-5p & UAGCAGCACGUAAAUAUUGGCG & $\uparrow$ & \multirow{3}{*}{ Plasma } & 2761 \\
\hline hsa-miR-23b-3p & AUCACAUUGCCAGGGAUUACCAC & $\downarrow$ & & 2284 \\
\hline hsa-miR-92a-3p & UAUUGCACUUGUCCCGGCCUGU & $\uparrow$ & & 1238 \\
\hline hsa-let-7e-5p & UGAGGUAGGAGGUUGUAUAGUU & $\downarrow$ & \multirow{6}{*}{ Saliva } & 1387 \\
\hline hsa-miR-181a-5p & AACAUUCAACGCUGUCGGUGAGU & $\uparrow$ & & 1597 \\
\hline hsa-miR-181c-5p & AACAUUCAACCUGUCGGUGAGU & $\uparrow$ & & 1798 \\
\hline hsa-miR-25-3p & CAUUGCACUUGUCUCGGUCUGA & $\uparrow$ & & 1407 \\
\hline hsa-miR-34a-5p & UGGCAGUGUCUUAGCUGGUUGU & $\downarrow$ & & 1330 \\
\hline hsa-miR-944 & AAAUUAUUGUACAUCGGAUGAG & $\uparrow$ & & 1178 \\
\hline
\end{tabular}

lected in serum, 10 in plasma, and 22 in saliva (Fig. 2B). These deregulated miRNAs served as peripheral indicators of molecular regulatory mechanisms involved after the mTBI. We identified the putative target genes for deregulated miRNAs in all three biofluids using the mirDIP database portal, and visualized the miRNA:gene networks illustrating the top genes targeted by the most of the deregulated miRNAs in serum vs. saliva (Fig. 3A), serum vs. plasma (Fig. 3B) and saliva vs. plasma (Fig. 3C). Combined, we predicted 9,903 target genes for deregulated serum miRNAs, 6,544 target genes for plasma miRNAs, and 12,343 for salivary miRNAs.

Key involved miRNAs targeting the highest number of genes in particular biofluids are summarized in Table 1, suggesting their higher predictive value for peripheral signaling after mTBI. Gene targets for each biofluid were separately analysed using pathDIP portal to identify enriched pathways. Overall, we identified 771 significantly enriched pathways in serum, 757 in plasma, and 710 in saliva after mTBI. Our analysis revealed that majority of identified enriched pathways is shared among the biofluids and only a fraction of enriched pathways is unique to a particular biological fluid (Fig. 4A). Additionally, word enrichment analysis uncovered that most of the highly ranked pathway terms (blue and purple edge colour) are common among two or all three biofluids. The top scored pathways associate with MAPK, TGF- $\beta$, WNT, TLR2/4, PI3K/AKT, insulin, and growth factor signaling. Main mTBI-associated pathophysiological pathways are listed in Table 2. However, we also identified enriched pathways unique for each of the studied biofluids (Fig. 4B). A comprehensive list of identified enriched pathways is provided in Supplement 3.

To investigate the link between TBI and neurodegeneration, we mapped identified gene targets of deregulated miRNAs (1,123 targets in serum, 1,007 in plasma and 1,792 in saliva) to proteins. Using IID we retrieved 52,605 direct, human physical protein-protein interactions among unique targets across the biofluids. The resulting network was

Table 2. Representative pathophysiological pathways associated with mild traumatic brain injury (mTBI) identified by pathway enrichment analysis

\begin{tabular}{llc}
\hline Pathway name & Pathway source & q-value \\
\hline PI3K/AKT/mTOR & ACSN2 & $6.08 \mathrm{E}-17$ \\
TGF-beta signaling & WikiPathways & $2.35 \mathrm{E}-12$ \\
Starvation_autophagy & ACSN2 & $2.59 \mathrm{E}-11$ \\
Canonical WNT & ACSN2 & $3.10 \mathrm{E}-11$ \\
EGF/EGFR signaling & WikiPathways & $4.46 \mathrm{E}-11$ \\
Insulin signaling & WikiPathways & $6.34 \mathrm{E}-11$ \\
VEGFA-VEGFR2 signaling & WikiPathways & $3.33 \mathrm{E}-09$ \\
BDNF signaling & WikiPathways & $5.51 \mathrm{E}-09$ \\
MAPK signaling & KEGG & $3.76 \mathrm{E}-08$ \\
FoxO signaling & KEGG & $1.40 \mathrm{E}-07$ \\
Endocytosis & KEGG & $5.15 \mathrm{E}-07$ \\
Regulation of actin cytoskeleton & KEGG & $6.37 \mathrm{E}-07$ \\
Toll-like receptor signalling & & \\
network & systems-biology.org & $8.84 \mathrm{E}-07$ \\
Focal adhesion & WikiPathways & $9.27 \mathrm{E}-07$ \\
Immunostimulatory core & ACSN2 & $3.42 \mathrm{E}-06$ \\
FGF signaling & Panther_Pathway & $4.11 \mathrm{E}-06$ \\
Apoptosis & ACSN2 & $7.16 \mathrm{E}-06$ \\
IGF1R signaling cascade & REACTOME & $2.03 \mathrm{E}-03$ \\
Growth factors signaling & ACSN2 & $6.95 \mathrm{E}-03$ \\
PTEN regulation & REACTOME & $7.85 \mathrm{E}-03$ \\
Synaptic vesicle trafficking & Panther_Pathway & $1.67 \mathrm{E}-02$ \\
IL-1 pathway & stke & $2.26 \mathrm{E}-02$ \\
\hline
\end{tabular}

Literature curated (core) pathways considering $q$-value $<0.05$ using the false discovery rate (FDR): Benjamini-Hochberg (BH) method. 
A

$-$

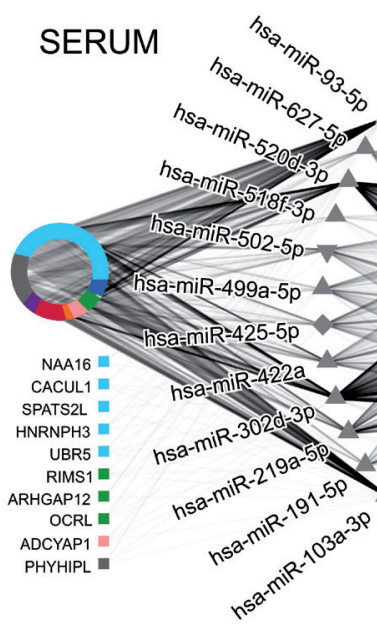

B

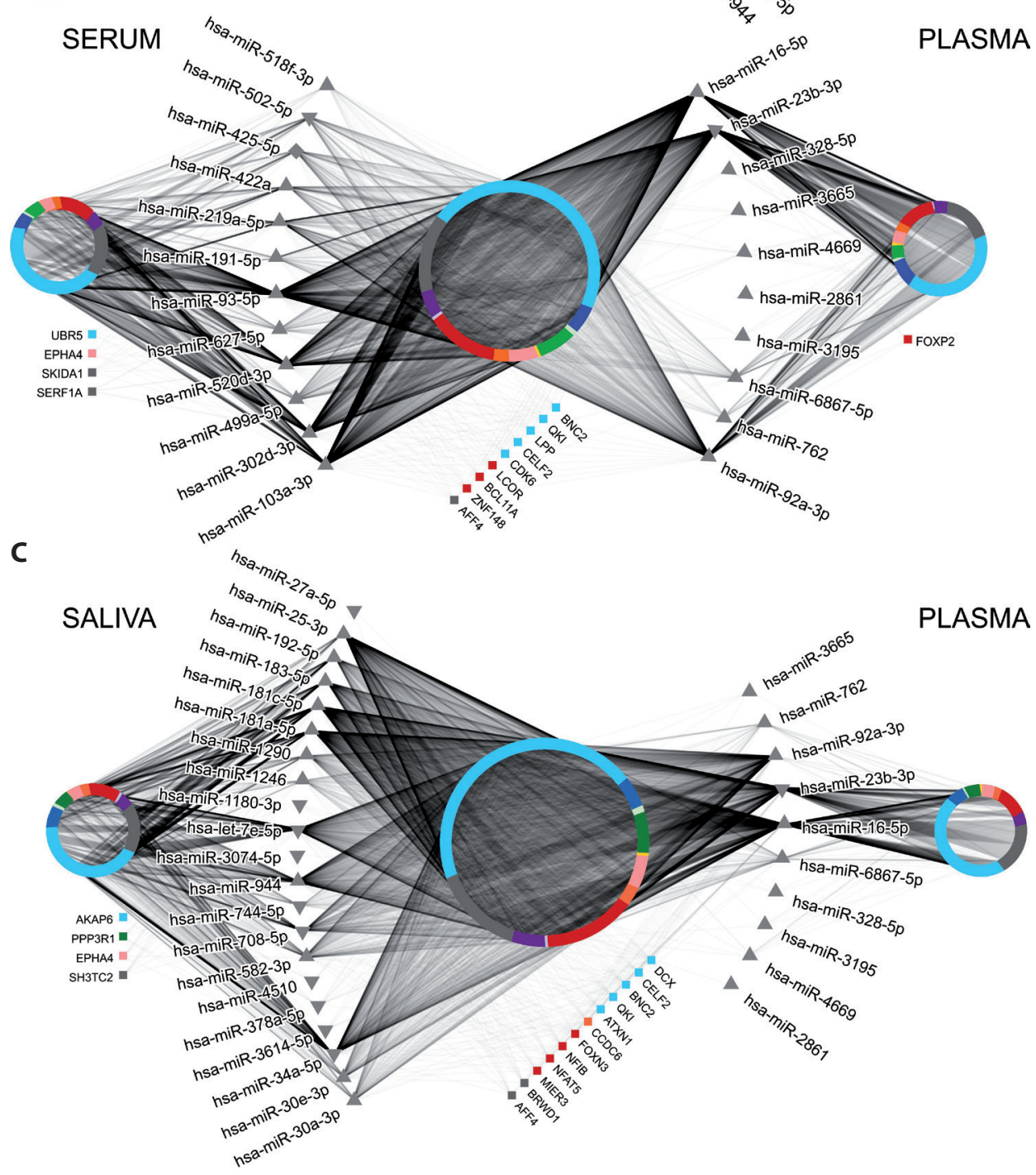

Node color: GO Molecular Function

Binding

Catalytic Activity

Channel Regulator Activity

Enzyme Regulator Activity

Regulation of Molecular Function

Transcription Factor Activity

Receptor Regulator Activity

Structural Molecule Activity

Translation Regulator Activity

Transporter Activity

Uncategorized

$\triangle$ Up-regulated

$\checkmark$ Down-regulated

Up- \& Down-

regulated

Figure 3. Target genes for deregulated miRNAs in biofluids as identified by mirDIP. Contrast miRNA:gene network for serum $v s$. saliva (A), serum $v s$. plasma (B) and saliva $v s$. plasma (C). Node colour for genes represents Gene ontology (GO) molecular function, and node shape for miRNAs highlights experimental evidence, as per legend. Genes listed by symbol are targeted by most of the deregulated miRNAs, in a given biofluid or in both as considered in the respective contrast network. 
A

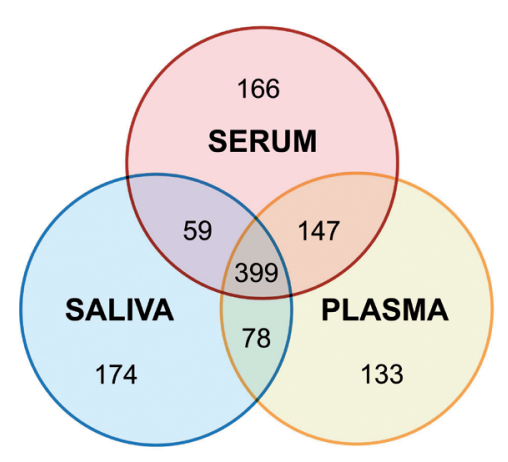

B

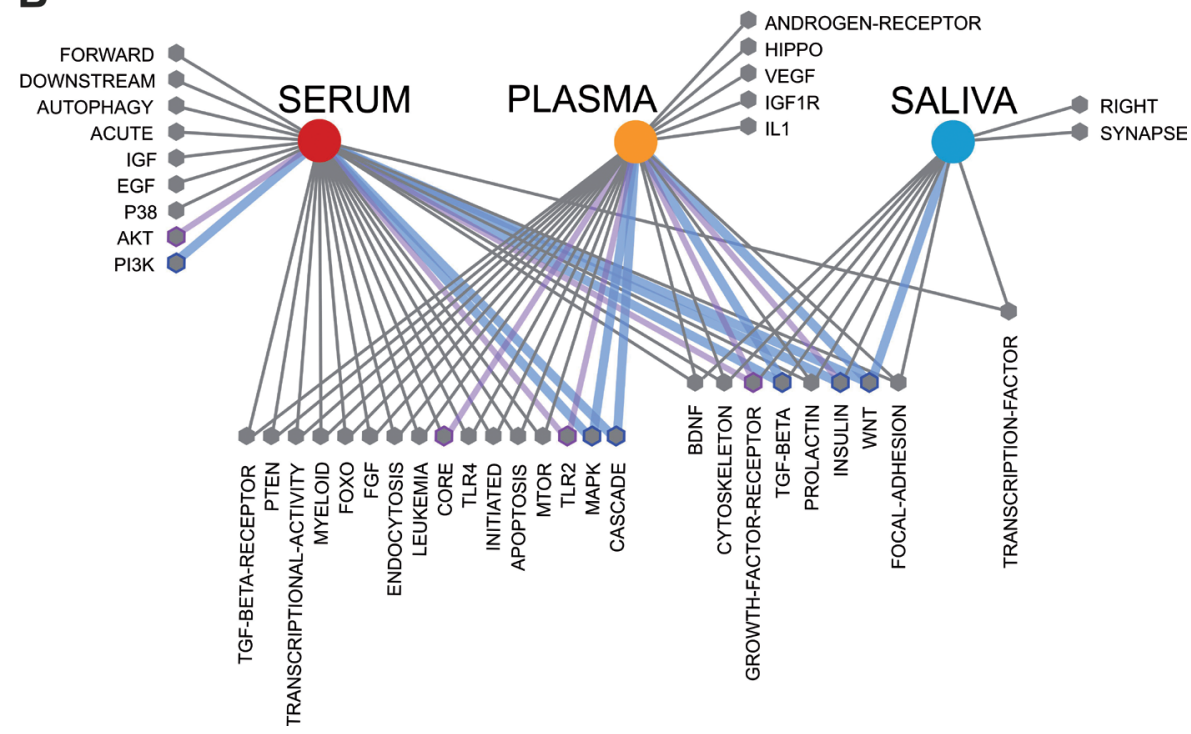

Figure 4. Pathway enrichment analysis using pathDIP. A. The number of identified enriched pathways and their overlap among the serum, plasma, and saliva. B. The most overrepresented enriched pathways show many shared terms. Edge colour and thickness represents significance of term enrichment (blue, purple, and black refers to low-to-higher $q$-value).

further filtered by selecting only the interactions related to neurodegeneration and focusing on central proteins within the network. Final network comprised 33 key hub proteins connected with interactions relevant in neurodegeneration, nervous system disease, tauopathy and Alzheimer's disease. Furthermore, we highlighted in the network the deregulated miRNAs that are linked to these key hub proteins associated with neurodegeneration (Fig. 5). Interestingly, among the interactions we identified several dominant connections that link deregulated miRNAs and identified proteins. Specifically, overrepresentation of the miR-93-5p, miR-302d-3p, miR-520d-3p in serum, miR-16-5p, miR-23b-3p in plasma and let-7e-5p, miR-34a-5p, miR-181a-5p, mir-181c-5p, miR-183-5p, miR-744-5p in saliva with neurodegeneration-associated proteins was observed. These deregulated miRNAs represent a group of candidate molecules linking the post-mTBI signaling reflected in peripheral fluids with neurodegeneration-associated interaction pathways. Final list of interacting proteins is attached in the Supplement 4.

\section{Discussion}

We performed a systematic review of deregulated miRNA profiles in peripheral fluids of individuals suffering mild traumatic brain injury aiming to identify molecular signaling associated with pathophysiology of mTBI. The meta-analysis specifically focused on studies that summarize the altered miRNA level in serum, plasma, and saliva of mTBI individu- als. Following selection criteria, the search strategy identified 8 studies providing data on 44 deregulated miRNAs that were further analysed by bioinformatic pipeline. Integrated bioinformatic workflow enabled both increased coverage and depth of our analysis by simultaneous querying of multiple databases for more comprehensive prediction of putative gene targets and higher confidence of the outcomes when compared to recent analyses (Di Pietro et al. 2017, 2018; Atif and Hicks 2019).

\section{miRNA:gene networks}

Highlighted subgroups of identified genes visualized in the miRNA:gene networks (Fig. 3) represent a subset of genes targeted by the highest number of deregulated miRNAs across all biofluids after mTBI. Moreover, one of the target genes, CACUL1, was previously described as a target of miR-219a-5p that has been found deregulated after TBI. Experimental validation of CACUL1 expression in the neuronal cell injury model revealed caspase-3-dependent induction of apoptosis regulated by Akt/Foxo3a and p53/ Bcl-2 signaling pathways (Yan et al. 2019). Upregulation of another predicted target gene, GCLM, has been described in the TBI mice model as one of the downstream genes of Nrf2 signaling pathway, playing a neuroprotective role following TBI (Dong et al. 2018). Furthermore, decreased level of CUL5 as measured in rat cerebral cortex and hippocampus 7 days post-TBI was linked to the inhibition of ubiquitin-proteasome system (Yao et al. 2006). The neu- 
roprotective effect of $A D C Y A P 1$, also known as pituitary adenylate cyclase activating polypeptide (PACAP), has been investigated in the rat model of diffuse axonal injury. Intracerebroventricular administration of PACAP following TBI resulted in a reduction of beta-amyloid precursor protein-immunopositive axons in the corticospinal tract (Farkas et al. 2004; Tamas et al. 2006). Involvement of EPHA4 has been observed in pro-inflammatory response to TBI via regulation of Akt, mTOR, and NF- $\mathrm{kB}$ signaling pathways (Kowalski et al. 2019).

Deregulation of miRNA levels in brain or peripheral fluids was extensively studied in various animal models of TBI. Despite a certain overlap of miRNA findings, the accumulated evidence indicates major difference between animal models and human TBI studies (Pinchi et al. 2020; Herrold et al. 2021). Nevertheless, animal models still carry the translation potential of research findings for diagnostic or therapeutic benefits in human medicine. In particular, upregulation of 2 miRNAs that are highly expressed in the brain, the miR9-3p and miR-136-3p was reported in plasma of TBI rats and mTBI patients suggesting their biomarker potential (Das Gupta et al. 2021). Other promising miRNAs, such as miR-142-3p (Liu et al. 2014b), let-7i (Balakathiresan et al. 2012), miR-23b (Sun et al. 2018), miR-181a-5p and miR191-5p (Weisz et al. 2020) were identified in both human and animals, indicating shared post-concussive signaling between TBI animal models and clinical studies.

Our findings suggest an association of identified genes with development and functioning of central nervous system indicating specific molecular signaling involved in mTBI. Employing the integrative approach, we were able to predict the gene candidates linked to the post-traumatic sequelae of TBI depicting the brain injury pathways together with particular healing processes. Our data are partially supported by experimental evidence; however, vast majority of drawn gene predictions is novel and remains to be explored by further functional and clinical studies. Moreover, we hypothesize that identified top ranked genes might represent a group of potential novel biomarkers to be further explored in connection with TBI conditions.

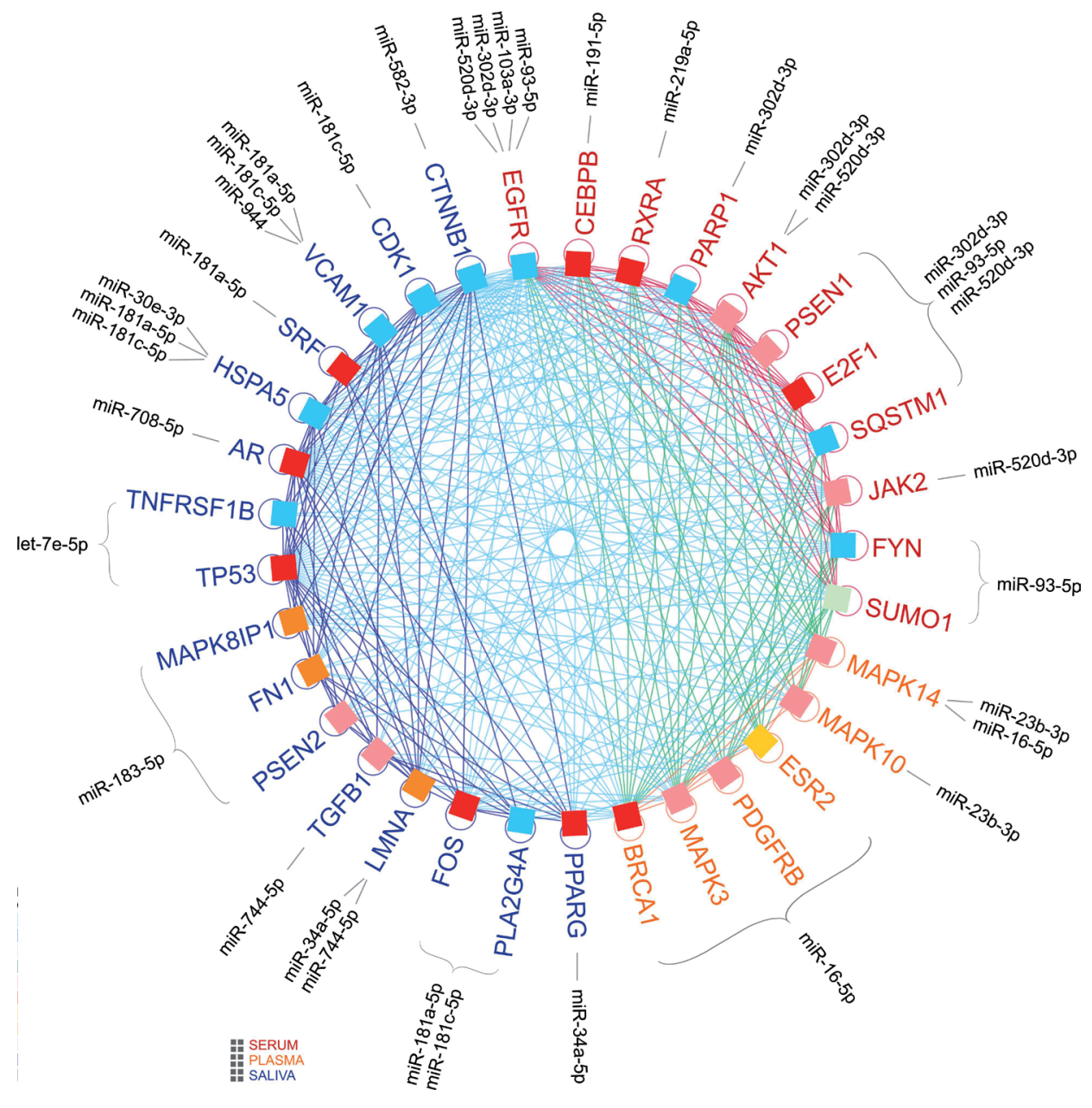

\author{
Node color: \\ GO Molecular Function \\ Binding \\ Catalytic Activity \\ Channel Regulator Activity \\ Enzyme Regulator Activity \\ Regulation of Molecular Function \\ Transcription Factor Activity \\ Receptor Regulator Activity \\ Structural Molecule Activity \\ Translation Regulator Activity \\ Transporter Activity \\ Uncategorized
}

Figure 5. Protein-protein interactions among predicted target genes of miRNAs deregulated in mTBI. Node colour represents Gene Ontology (GO) molecular function, and text colour highlights biofluid source, as per legend. Edges represent neurodegeneration-related interactions, while edge colour signifies relationships among proteins - dark blue edges are among saliva targets, red edges among serum targets, orange among plasma targets, green edges are between serum and plasma targets, and turquoise between serum/plasma and CSF targets. 


\section{Signaling pathways altered after mTBI}

Interestingly, the majority of the signaling pathways as derived from the deregulated peripheral miRNAs after mTBI are shared among the investigated biofluids of serum, plasma and saliva. According to these findings, dysregulated circulating miRNAs target the genes implicated in the same fundamental mechanisms simultaneously manifested in all assessed biofluids. These data support the idea that different biological fluids carry the molecular information on pathophysiological processes related to brain injury and might help to better elucidate the gene signaling or predict targets for therapeutical intervention of TBI.

Among the significantly enriched pathways the disturbance of hormone signaling represents the most prominent feature identified by bioinformatic analysis. Posttraumatic neuroendocrine dysfunction, e.g., hypopituitarism is a welldocumented consequence of TBI (Benvenga et al. 2000; Kelly et al. 2000). Besides disturbances of other anterior pituitary hormones, higher prolactin level has been reported in soldiers who sustained blast-induced TBI (Baxter et al. 2013). Likewise, mild hyperprolactinemia was observed in mild to severe TBI patients (Aimaretti et al. 2004). A higher level of prolactin following TBI can be explained by transport repression of prolactin inhibitory factor into the pituitary gland (Scranton and Baskin 2015). The pituitary dysfunction has been associated with a decreased serum level of insulin like growth factor 1 (IGF-1), suspected to be also involved in the progression of cognitive dysfunction (Bondanelli et al. 2004; Berg et al. 2010). Inversely, administration of IGF-1 leads to stimulation of anti-apoptotic pathways mediated by PI3K/Akt and MAPK signals and prevents spatial memory deficits following mTBI in mice (Rubovitch et al. 2010, 2011). Stimulation of these cascades appears to be a promising strategy positively affecting the recovery mechanisms such as angiogenesis, anti-apoptotic survival, synaptic plasticity and neurogenesis (Mangiola et al. 2015).

Findings identified by our analysis are further supported by a recent study that revealed association of 5 deregulated miRNAs with insulin, IGF-1R and TGF- $\beta$ signaling in military personnel with history of mTBI (Devoto et al. 2020).

Pleiotropic cytokine, transforming growth factor-beta (TGF- $\beta$ ), plays a role in neurogenesis, removal of amyloid- $\beta$ protein and modulates the actions of various growth factors (Devoto et al. 2020). The general effect of TGF- $\beta$ in TBI models remains questionable, but its neuroprotective function relates to the restriction of chemokines production after brain injury (Dobolyi et al. 2012). Potential pro-apoptotic function of TGF- $\beta$ through activation of the caspase- 3 in rats with induced mTBI was also reported (Patel et al. 2017).

The enrichment of TGF- $\beta$ signaling, as reflected by all examined biofluids in our study, supports the idea that this pathway plays an important role in post-concussive signaling and might represent a viable candidate for management of post-traumatic sequelae in mTBI patients.

Another highly over-represented class of signaling pathways identified by our meta-analysis includes the group of various growth factors and receptors. One of the identified enriched signaling pathways, the vascular endothelial growth factor (VEGF), was previously reported in connection with angiogenesis, neurogenesis and neuroprotection in TBI models (Nag et al. 1997; Sun et al. 2003; Thau-Zuchman et al. 2010; Lu et al. 2019). A higher concentration of VEGF has been also reported in humans suffering traumatic brain injury with various severities (Mellergard et al. 2010; Helmy et al. 2011; Meabon et al. 2020). Recently, elevated plasma levels of VEGF, together with IL- 6 and TNF- $a$ were associated with CT lesions in patients following mTBI. It seems that a combination of these three molecules could represent a biomarker panel to distinguish mTBI cases with CT findings from mTBI without CT findings (Edwards et al. 2020b).

TBI was shown to evoke the sensitivity of cells to epidermal growth factor (EGF) cascade via increase of EGFR levels (Addington et al. 2015). Furthermore, neuroprotective effect of EGF in post-concussive period is mediated by stimulation of astroglial cells, which leads to improved cognitive function and reduced neuronal loss (Sun et al. 2010). Similarly to EGF, the pro-survival function of fibroblast growth factor (FGF) relates to its mitogen activity restricting the apoptosis and necrosis via inhibition of autophagy (Addington et al. 2015; Tang et al. 2017). A study on patients also confirmed the role of FGF in neurogenesis and protection of blood brain barrier (Chaban et al. 2020). Brain-derived neurotrophic factor (BDNF) plays a regulatory role in neuronal survival, neurogenesis, and synaptic plasticity (Martinowich and $\mathrm{Lu}$ 2008). This effect is mediated via binding to TrkB receptor and activation of three signaling pathways: PI3K, MAPK/ERK, and PLC $\gamma$ (Chao 2003). The elevated plasma level of BDNF was previously observed in children with a concussion suggesting its potential use as a marker of mild head trauma. However, the BDNF levels did not differentiate the severe TBI with loss of consciousness from mTBI without loss of consciousness suggesting that BDNF increase indicates rather functional disturbance related to TBI as such and is not related to the severity of head trauma (Tylicka et al. 2020).

Growth factor signaling is associated with another important cascade of PI3K/Akt/mTOR. When activated, PI3K stimulates Akt serine/threonine kinase 1 (Akt) to trigger mTOR pathway that plays a crucial role in functional recovery process following a traumatic CNS injury (Don et al. 2012). Regulation of mTOR pathway via suppression of PTEN activates PI3K/Akt signaling leading to neuroprotection through regulation of apoptosis-related proteins (Ge et al. 2014; Han et al. 2014). 
Neuroinflammation represents an important mechanism in pathophysiology of TBI leading to secondary brain damage in post-traumatic period (Singh et al. 2016; Sun et al. 2019). Our results from bioinformatic analysis agree with previously identified molecules of inflammatory pathways activated in response to TBI, e.g., IL-1, TLR2 and TLR4. Pro-inflammatory cytokine, interleukin 1 (IL-1), is an important mediator of neuroinflammatory response after TBI (Basu et al. 2004). Both IL-1 $\alpha$ and IL-1 $\beta$ have been described previously as rapidly elevated after brain injury (Griffin et al. 1994; Fan et al. 1995). Furthermore, the genetic ablation of IL-1 receptor showed a more positive effect on cognitive function in TBI mice models than ablation of IL-1 $\alpha$ and IL-1 $\beta$ alone (Newell et al. 2018). High level of inflammatory cytokines including IL-1 $\beta$, IL- 6 and CCL 2 was acutely elevated in mTBI patients relative to controls. However, the elevated CCL2 level was also associated with greater severity of post-concussion symptoms negatively affecting the outcome of mTBI patients (Sun et al. 2019). These observations highlight the deleterious effect of pro-inflammatory signaling in post-injury period when persisting chronically.

Toll-like receptors (TLR) represent another group of highly enriched signaling pathways identified by our analysis. TLRs have been recognized as essential players of innate immune signaling and regulation of inflammatory responses (Kawai and Akira 2006). Even in the post-TBI conditions activation of TLR 2/4 involves signaling via MAPKs and subsequent stimulation of NF- $\kappa \mathrm{B}$ leading to expression of inflammation responsive genes (Downes and Crack 2010; Ved et al. 2021). TLR2/4-mediated secondary brain injury was observed proposing their role in neuroinflammation and cell death (Krieg et al. 2017), while the TLR4/MyD88/ NF- $\kappa \mathrm{B}$ signaling pathway might be efficiently targeted by PACAP reducing the secondary inflammatory response and neuronal death after TBI (Mao et al. 2012).

Metabolic disturbance is another invariant feature of post-concussive condition in TBI patients.

Studies have shown occurrence of hyperglycolysis early after injury, followed by a hypometabolic phase lasting for days (Yoshino et al. 1991; Bergsneider et al. 2001). A high glucose level during the first hours after TBI can predict a poor neurologic outcome and mortality rate (Liu-DeRyke et al. 2009; Terzioglu et al. 2015). Additionally, the association between diabetes and increased risk of neurodegeneration developed due head trauma has been reported in veterans with type 2 diabetes and a history of TBI (Zimering et al. 2019). Possible molecular explanation suggests that elevated pro-inflammatory cytokines inhibit insulin receptor signaling by targeting the Akt that negatively affects the neuronal energy metabolism. Furthermore, insulin resistance following TBI deprives this neuroprotective pathway and thus renders the individuals vulnerable to neurodegeneration (Karelina and Weil 2016).
WNT signaling is involved in several critical processes in the brain, including cell proliferation, differentiation, inflammation, neurogenesis, synaptogenesis, axon guidance, neuron maintenance, and regeneration (Salinas 2012; Marchetti and Pluchino 2013). Various studies implicate the WNT pathway as a neuroprotective cascade that upon stimulation might represent a prospective treatment of post-TBI conditions (Zhao et al. 2016; Zhang et al. 2018). Intranasal administration of recombinant Wnt3a in TBI mice model during first 24 hours was shown to inhibit the autophagy and upregulate the expression of growth factors including GDNF and VEGF responsible for neurogenesis and angiogenesis, respectively. In our meta-analysis, WNT pathway has been the top ranked prediction in all examined fluids, suggesting a key role of WNT pathway in post-traumatic signaling and recovery.

Previous studies used various bioinformatic approaches to identify signaling pathways linked to deregulated miRNAs after TBI. However, the published pathways were derived from a single database, e.g., KEGG or Ingenuity Pathway analysis, respectively, leading to only partial results due to small overlap across pathway databases (Rahmati et al. 2017). Despite this methodological limitation the mTOR, TGF-beta, IGF1R, neurotrophin and inflammatory signaling represent major overlap with findings of our meta-analysis and support their involvement in post mTBI conditions by multiple evidence (Qin et al. 2018; Atif and Hicks 2019; Devoto et al. 2020; Hicks et al. 2020a; Di Pietro et al. 2021).

\section{Link between mTBI and neurodegeneration}

The history of mTBI, and especially the repetitive head traumas are associated with increased risk of development of neurodegenerative disorders (McKee and Robinson 2014; Manley et al. 2017; Alosco et al. 2018). To elucidate the relationship between prior TBI with subsequent dementia we tested the hypothesis how molecular signaling identified after mTBI relates to the protein interactions seen in neurodegeneration including Alzheimer's disease and tauopathies. Bioinformatic analysis revealed group of genes targeted by deregulated miRNAs after mTBI with a known interaction in neurodegenerative conditions. Within this subpopulation several central proteins implicated in the neurodegenerative disorders were identified. In particular, the Alzheimer's disease-associated proteins, presenilin 1 (PSEN1) and presenilin 2 (PSEN2) showed major interactions within the network.

PSEN1 via increase of cytoplasmic CTNNB1, another identified key hub protein within the network, negatively regulates the WNT and Notch signaling (Murayama et al. 1998; Marambaud et al. 2002). Since these pathways play an important role in neuroregeneration and brain homeostasis, downregulation of this signaling by TBI might negatively affect the process of recovery and contribute to the longi- 
tudinal sequelae of TBI, which might eventually progress towards neurodegeneration. Furthermore, targeting of gamma-secretase complex including presenilin to reduce amyloid beta production represents a perspective therapeutic strategy for treatment of Alzheimer's disease (De Strooper et al. 2012), and might be potentially employed also for the attenuation of neurotrauma following TBI (Mannix et al. 2011; Lin et al. 2017).

In addition, among the key hub proteins identified within the protein interaction network, there are several other candidates that have been previously reported in connection with TBI. Up-regulation of AKT1 (Edwards et al. 2020a), FOS (Wang et al. 2014), FYN (Liu et al. 2014a), MAPK3 (Ou et al. 2014), CEBPB (Sandhir and Berman 2010), PLA2G4A (Sarkar et al. 2020), RXRA (Zhao et al. 2019), E2F1 (Liu et al. 2013), HSPA5 (Truettner et al. 2007) and downregulation of AR (Golz et al. 2019), MAPK10 (Long et al. 2013) was observed in various animal TBI models or human TBI cases. While the increase of HSPA5 is thought to be neuroprotective in neurodegeneration (Casas 2017), the activation of E2F1 is associated with posttraumatic neuronal apoptosis (Liu et al. 2013). Activation of JAK2-STAT3 pathway together with upregulation of CEBPB couples the activation of astrocytes with growth factor and neuroinflammatory responses after TBI (Oliva et al. 2012). Along with these findings the TNFRSF1B and SRF-deficient mice exhibit poorer outcome following TBI (Yang et al. 2010; Forstner and Knoll 2020). On the other side experimental administration of EGF (Sun et al. 2010) and FN1 (Tate et al. 2007) in animal TBI models suggests their neuroprotective role. Furthermore, the upregulation of CDK1 by dexmedetomidine (Wu et al. 2018; Yang et al. 2021) and inhibition of PARP1 (Stoica et al. 2014) in TBI models also appears to be viable neuroprotective strategy.

Our study also identified a subgroup of proteins, e.g., BRCA1, LMNA and ESR2 that have not been associated with TBI so far, and thus might represent novel candidates for validation in TBI conditions.

Presence of validated targets within the protein interaction network supports the findings of integrated bioinformatic analysis with experimental evidence. Interestingly, the interaction network of neurodegeneration-associated proteins highlights the TGF- $\beta$, AKT1, MAPK, TP53, TNF and growth factor signaling that were also identified among the pathways enriched in mTBI. This overlap indicates overrepresentation of signaling related to these proteins and implicates their central role in molecular regulatory mechanisms shared between mTBI and neurodegeneration.

To our knowledge this is the first integrative bioinformatic analysis systematically combining comprehensive miRNA-target prediction, multiple pathway sources, and rich annotated physical protein interactions aiming to identify peripheral miRNA signaling associated with mild traumatic brain injury. Results of the integrative analysis reveal specific signaling pathways and highlight the key enriched molecular mechanisms reflected across the serum, plasma and saliva of individuals after mTBI. Findings of the meta-analysis suggest that peripheral miRNAs could represent relevant biomarkers with added value to the currently used diagnostic approaches and prognostics of recovery after TBI.

\section{Strengths and limitations}

Despite the supportive data for our findings in the scientific literature we assessed the risk of bias, among which the input miRNA data represent reasonable source of variability to be considered. In particular, various methodological approaches used for the measurement of miRNA, such as next-generation sequencing, real-time PCR or microarray techniques, provide a variable depth of information and sensitivity of detection for evaluated miRNAs. Furthermore, many studies lack the sample quality check or provide no statement about exclusion of low-quality samples prior analysis (e.g., hemolysis for plasma, contamination of saliva with cellular RNA). Third, use of different endogenous calibrators and normalization procedures for calculation of miRNA fold change has to be considered as it has a direct impact on accuracy of reported miRNA expression values. Fourth, variable statistical methods used in the research articles or lacking validation step of primary data obtained by whole transcriptome analysis might result in distinct pattern of false positives and negatives affecting the inclusion of miRNAs in the integrated analyses. We summarize these issues to be critically considered by the readers during interpretation of our findings.

On the other hand, the process of data curation accounted for multiple variable factors and data constraints providing more consistent data input when compared to previous metaanalyses. Evaluation of the data under the strict statistical and predictive parameters supports obtained findings at high confidence level. Moreover, we consider the use of integrative bioinformatic pipeline as a major advantage of the employed meta-analytic approach since it enables the identification of enriched signaling pathways and molecular mechanisms based on cumulative support from multiple database sources and thus to a substantial degree corrects for the variabilities of input experimental data.

\section{Conclusions}

Integrated bioinformatic analysis revealed enrichment of common signaling pathways involved in the post-concussive conditions as reflected by the profile of circulating miRNAs in various body fluids. Since the identified pathways sub- 
stantially overlap among the biofluids we hypothesize that the specific signaling associated with mTBI is concomitantly reflected in various biological fluids. Furthermore, our data indicate that biofluid-specific miRNA profiles could serve for detailed characterization of molecular pathways involved in the pathophysiology and healing processes of mild traumatic brain injury. Top hub proteins identified within the network represent novel putative candidates involved in molecular signaling after mTBI. Our findings implicate a molecular link between mTBI signaling and neurodegeneration-associated interaction pathways. However, to validate the concept of mTBI-induced neurodegeneration involving predicted targets further experimental research is necessary.

Acknowledgement. Bioinformatic analyses were in part supported by the Ministry of Education of the Slovak Republic, awarded to BrainTest, s.r.o. within the research scheme "Stimuli for research and development" and research grants VEGA 2/0118/19, VEGA 2/0154/19 and APVV-17-0668, APVV-19-0568, APVV-20-0615. We are grateful to Zlatica Cerna for her help with graphical design and artistic illustration. Development and maintenance of used tools and databases were supported in part by funding from Natural Sciences Research Council (NSERC \#203475), Canada Foundation for Innovation (CFI \#225404, \#30865), Ontario Research Fund (RDI \#34876), IBM and Ian Lawson van Toch Fund. The funders had no role in study design, data collection and analysis, decision to publish, or preparation of the manuscript.

Conflict of interest. The authors declare no conflict of interest.

\section{References}

Addington CP, Roussas A, Dutta D, Stabenfeldt SE (2015): Endogenous repair signaling after brain injury and complementary bioengineering approaches to enhance neural regeneration. Biomark Insights 10, 43-60 https://doi.org/10.4137/BMI.S20062

Aimaretti G, Ambrosio MR, Di Somma C, Fusco A, Cannavo S, Gasperi M, Scaroni C, De Marinis L, Benvenga S, degli Uberti EC et al. (2004): Traumatic brain injury and subarachnoid haemorrhage are conditions at high risk for hypopituitarism: screening study at 3 months after the brain injury. Clin. Endocrinol. (Oxf). 61, 320-326 https://doi.org/10.1111/j.1365-2265.2004.02094.x

Alosco ML, Koerte IK, Tripodis Y, Mariani M, Chua AS, Jarnagin J, Rahimpour Y, Puzo C, Healy RC, Martin B et al. (2018): White matter signal abnormalities in former National Football League players. Alzheimers Dement. (Amst). 10, 56-65 https://doi.org/10.1016/j.dadm.2017.10.003

Atif H, Hicks SD (2019): A review of microRNA biomarkers in traumatic brain injury. J. Exp. Neurosci. 13, 1179069519832286 https://doi.org/10.1177/1179069519832286

Bailes JE, Petraglia AL, Omalu BI, Nauman E, Talavage T (2013): Role of subconcussion in repetitive mild traumatic brain injury. J. Neurosurg. 119, 1235-1245 https://doi.org/10.3171/2013.7.JNS121822
Balakathiresan N, Bhomia M, Chandran R, Chavko M, McCarron RM, Maheshwari RK (2012): MicroRNA let-7i is a promising serum biomarker for blast-induced traumatic brain injury. J. Neurotrauma 29, 1379-1387

https://doi.org/10.1089/neu.2011.2146

Basu A, Krady JK, Levison SW (2004): Interleukin-1: a master regulator of neuroinflammation. J. Neurosci. Res. 78, 151-156 https://doi.org/10.1002/jnr.20266

Baxter D, Sharp DJ, Feeney C, Papadopoulou D, Ham TE, Jilka S, Hellyer PJ, Patel MC, Bennett AN, Mistlin A et al. (2013): Pituitary dysfunction after blast traumatic brain injury: The UK BIOSAP study. Ann. Neurol. 74, 527-536 https://doi.org/10.1002/ana.23958

Benvenga S, Campenni A, Ruggeri RM, Trimarchi F (2000): Clinical review 113: Hypopituitarism secondary to head trauma. J. Clin. Endocrinol. Metab. 85, 1353-1361 https://doi.org/10.1210/jcem.85.4.6506

Berg C, Oeffner A, Schumm-Draeger PM, Badorrek F, Brabant G, Gerbert B, Bornstein S, Zimmermann A, Weber M, BroeckerPreuss $\mathrm{M}$ et al. (2010): Prevalence of anterior pituitary dysfunction in patients following traumatic brain injury in a German multi-centre screening program. Exp. Clin. Endocrinol. Diabetes 118, 139-144 https://doi.org/10.1055/s-0029-1225611

Bergsneider M, Hovda DA, McArthur DL, Etchepare M, Huang SC, Sehati N, Satz P, Phelps ME, Becker DP (2001): Metabolic recovery following human traumatic brain injury based on FDG-PET: time course and relationship to neurological disability. J. Head Trauma Rehabil. 16, 135-148 https://doi.org/10.1097/00001199-200104000-00004

Bondanelli M, De Marinis L, Ambrosio MR, Monesi M, Valle D, Zatelli MC, Fusco A, Bianchi A, Farneti M, degli Uberti EC (2004): Occurrence of pituitary dysfunction following traumatic brain injury. J. Neurotrauma 21, 685-696 https://doi.org/10.1089/0897715041269713

Brown KR, Otasek D, Ali M, McGuffin MJ, Xie W, Devani B, Toch IL, Jurisica I (2009): NAViGaTOR: Network Analysis, Visualization and Graphing Toronto. Bioinformatics 25, 3327-3329 https://doi.org/10.1093/bioinformatics/btp595

Bryant RA, Harvey AG (1998): Relationship between acute stress disorder and posttraumatic stress disorder following mild traumatic brain injury. Am. J. Psychiatry 155, 625-629 https://doi.org/10.1176/ajp.155.5.625

Casas C (2017): GRP78 at the Centre of the Stage in cancer and neuroprotection. Front Neurosci. 11, 177 https://doi.org/10.3389/fnins.2017.00177

Cassidy JD, Carroll LJ, Peloso PM, Borg J, von Holst H, Holm L, Kraus J, Coronado VG, et al. (2004): Incidence, risk factors and prevention of mild traumatic brain injury: results of the WHO Collaborating Centre Task Force on Mild Traumatic Brain Injury. J. Rehabil. Med. 43, 28-60 https://doi.org/10.1080/16501960410023732

Chaban V, Clarke GJB, Skandsen T, Islam R, Einarsen CE, Vik A, Damas JK, Mollnes TE, Haberg AK, Pischke SE (2020): Systemic inflammation persists the first year after mild traumatic brain injury: results from the prospective trondheim mild traumatic brain injury study. J. Neurotrauma 37, 2120-2130 https://doi.org/10.1089/neu.2019.6963 
Chao MV (2003): Neurotrophins and their receptors: a convergence point for many signalling pathways. Nat. Rev. Neurosci. 4, 299-309 https://doi.org/10.1038/nrn1078

Das Gupta S, Ciszek R, Heiskanen M, Lapinlampi N, Kukkonen J, Leinonen V, Puhakka N, Pitkanen A (2021): Plasma miR-9-3p and $\mathrm{miR}-136-3 \mathrm{p}$ as potential novel diagnostic biomarkers for experimental and human mild traumatic brain injury. Int. J. Mol. Sci. 22, 1563 https://doi.org/10.3390/ijms22041563

De Strooper B, Iwatsubo T, Wolfe MS (2012): Presenilins and gamma-secretase: structure, function, and role in Alzheimer disease. Cold Spring Harb. Perspect. Med. 2, a006304 https://doi.org/10.1101/cshperspect.a006304

Devoto C, Lai C, Qu BX, Guedes VA, Leete J, Wilde E, Walker WC, Diaz-Arrastia R, Kenney K, Gill J (2020): Exosomal microRNAs in military personnel with mild traumatic brain injury: preliminary results from the chronic effects of neurotrauma Consortium Biomarker Discovery project. J. Neurotrauma 37, 2482-2492 https://doi.org/10.1089/neu.2019.6933

Dewan MC, Rattani A, Gupta S, Baticulon RE, Hung YC, Punchak M, Agrawal A, Adeleye AO, Shrime MG, Rubiano AM et al. (2019): Estimating the global incidence of traumatic brain injury. J. Neurosurg. 130, 1080-1097 https://doi.org/10.3171/2017.10.JNS17352

Di Pietro V, Ragusa M, Davies D, Su Z, Hazeldine J, Lazzarino G, Hill LJ, Crombie N, Foster M, Purrello M et al. (2017): MicroRNAs as novel biomarkers for the diagnosis and prognosis of mild and severe traumatic brain injury. J. Neurotrauma 34, 1948-1956 https://doi.org/10.1089/neu.2016.4857

Di Pietro V, Yakoub KM, Scarpa U, Di Pietro C, Belli A (2018): MicroRNA signature of traumatic brain injury: from the biomarker discovery to the point-of-care. Front. Neurol. 9, 429 https://doi.org/10.3389/fneur.2018.00429

Di Pietro V, O'Halloran P, Watson CN, Begum G, Acharjee A, Yakoub KM, Bentley C, Davies DJ, Iliceto P, Candilera G et al. (2021): Unique diagnostic signatures of concussion in the saliva of male athletes: the Study of Concussion in Rugby Union through MicroRNAs (SCRUM). Br. J. Sports Med. (in press) https://doi.org/10.1136/bjsports-2020-103274

Dobolyi A, Vincze C, Pal G, Lovas G (2012): The neuroprotective functions of transforming growth factor beta proteins. Int. J. Mol. Sci. 13, 8219-8258 https://doi.org/10.3390/ijms13078219

Don AS, Tsang CK, Kazdoba TM, D’Arcangelo G, Young W, Zheng XF (2012): Targeting mTOR as a novel therapeutic strategy for traumatic CNS injuries. Drug Discov. Today 17, 861-868 https://doi.org/10.1016/j.drudis.2012.04.010

Dong W, Yang B, Wang L, Li B, Guo X, Zhang M, Jiang Z, Fu J, Pi J, Guan D et al. (2018): Curcumin plays neuroprotective roles against traumatic brain injury partly via Nrf2 signaling. Toxicol. Appl. Pharmacol. 346, 28-36 https://doi.org/10.1016/j.taap.2018.03.020

Downes CE, Crack PJ (2010): Neural injury following stroke: are Toll-like receptors the link between the immune system and the CNS? Br. J. Pharmacol. 160, 1872-1888 https://doi.org/10.1111/j.1476-5381.2010.00864.x

Edwards KA, Motamedi V, Osier ND, Kim HS, Yun S, Cho YE, Lai C, Dell KC, Carr W, Walker P et al. (2020a): A moderate blast exposure results in dysregulated gene network activity related to cell death, survival, structure, and metabolism. Front. Neurol. 11, 91

https://doi.org/10.3389/fneur.2020.00091

Edwards KA, Pattinson CL, Guedes VA, Peyer J, Moore C, Davis T, Devoto C, Turtzo LC, Latour L, Gill JM (2020b): Inflammatory cytokines associate with neuroimaging after acute mild traumatic brain injury. Front. Neurol. 11, 348 https://doi.org/10.3389/fneur.2020.00348

Fan L, Young PR, Barone FC, Feuerstein GZ, Smith DH, McIntosh TK (1995): Experimental brain injury induces expression of interleukin-1 beta mRNA in the rat brain. Brain Res. Mol. Brain Res. 30, 125-130 https://doi.org/10.1016/0169-328X(94)00287-O

Farkas O, Tamas A, Zsombok A, Reglodi D, Pal J, Buki A, Lengvari I, Povlishock JT, Doczi T (2004): Effects of pituitary adenylate cyclase activating polypeptide in a rat model of traumatic brain injury. Regul. Pept. 123, 69-75 https://doi.org/10.1016/j.regpep.2004.05.014

Forstner P, Knoll B (2020): Interference of neuronal activitymediated gene expression through serum response factor deletion enhances mortality and hyperactivity after traumatic brain injury. FASEB J. 34, 3855-3873 https://doi.org/10.1096/f.201902257RR

Gallant C, Barry N, Good D (2018): Physiological underarousal as a mechanism of aggressive behavior in university athletes with a history of concussion. Brain Behav. 8, e01038 https://doi.org/10.1002/brb3.1038

Gardner RC, Byers AL, Barnes DE, Li Y, Boscardin J, Yaffe K (2018): Mild TBI and risk of Parkinson disease: A chronic effects of neurotrauma consortium study. Neurology 90, e1771-e1779 https://doi.org/10.1212/WNL.0000000000005522

Ge XT, Lei P, Wang HC, Zhang AL, Han ZL, Chen X, Li SH, Jiang RC, Kang CS, Zhang JN (2014): miR-21 improves the neurological outcome after traumatic brain injury in rats. Sci. Rep. 4, 6718 https://doi.org/10.1038/srep06718

Gilbert KS, Kark SM, Gehrman P, Bogdanova Y (2015): Sleep disturbances, TBI and PTSD: Implications for treatment and recovery. Clin. Psychol. Rev. 40, 195-212 https://doi.org/10.1016/j.cpr.2015.05.008

Golz C, Kirchhoff FP, Westerhorstmann J, Schmidt M, Hirnet T, Rune GM, Bender RA, Schafer MKE (2019): Sex hormones modulate pathogenic processes in experimental traumatic brain injury. J. Neurochem. 150, 173-187 https://doi.org/10.1111/jnc. 14678

Griffin WS, Sheng JG, Gentleman SM, Graham DI, Mrak RE, Roberts GW (1994): Microglial interleukin-1 alpha expression in human head injury: correlations with neuronal and neuritic beta-amyloid precursor protein expression. Neurosci. Lett. 176, 133-136 https://doi.org/10.1016/0304-3940(94)90066-3

Han Z, Chen F, Ge X, Tan J, Lei P, Zhang J (2014): miR-21 alleviated apoptosis of cortical neurons through promoting PTEN-Akt signaling pathway in vitro after experimental traumatic brain injury. Brain Res. 1582, 12-20 
https://doi.org/10.1016/j.brainres.2014.07.045

Helmy A, Carpenter KL, Menon DK, Pickard JD, Hutchinson PJ (2011): The cytokine response to human traumatic brain injury: temporal profiles and evidence for cerebral parenchymal production. J. Cereb. Blood Flow Metab. 31, 658-670 https://doi.org/10.1038/jcbfm.2010.142

Herrold AA, Kletzel SL, Foecking EM, Saban KL, Przybycien-Szymanska MM, Zilliox M, Bhaumik D, Lange D, Radke JR, Salinas I et al. (2021): miRNAs as potential biomarkers for traumatic brain injury: pathway from diagnosis to neurorehabilitation. J. Head Trauma Rehabil. 36, E155-E169 https://doi.org/10.1097/HTR.0000000000000632

Hicks SD, Olympia RP, Onks C, Kim RY, Zhen KJ, Fedorchak G, DeVita S, Rangnekar A, Heller M, Zwibel H et al. (2020a): Saliva microRNA biomarkers of cumulative concussion. Int. J. Mol. Sci. 21, 7758 https://doi.org/10.3390/ijms21207758

Hicks SD, Onks C, Kim RY, Zhen KJ, Loeffert J, Loeffert AC, Olympia RP, Fedorchak G, DeVita S, Rangnekar A et al. (2020b): Diagnosing mild traumatic brain injury using saliva RNA compared to cognitive and balance testing. Clin. Transl. Med. 10, e197 https://doi.org/10.1002/ctm2.197

Iankova A (2006): The Glasgow Coma Scale: clinical application in emergency departments. Emerg. Nurse 14, 30-35 https://doi.org/10.7748/en2006.12.14.8.30.c4221

Iverson GL, Lovell MR, Smith S, Franzen MD (2000): Prevalence of abnormal CT-scans following mild head injury. Brain Inj. 14, 1057-1061 https://doi.org/10.1080/02699050050203559

Jorge RE, Robinson RG, Arndt SV, Starkstein SE, Forrester AW, Geisler F (1993): Depression following traumatic brain injury: a 1 year longitudinal study. J. Affect Disord. 27, 233-243 https://doi.org/10.1016/0165-0327(93)90047-N

Karelina K, Weil ZM (2016): Neuroenergetics of traumatic brain injury. Concussion 1, CNC9 https://doi.org/10.2217/cnc.15.9

Kawai T, Akira S (2006): TLR signaling. Cell Death Differ. 13, $816-825$ https://doi.org/10.1038/sj.cdd.4401850

Keller A, Rounge T, Backes C, Ludwig N, Gislefoss R, Leidinger P, Langseth H, Meese E (2017): Sources to variability in circulating human miRNA signatures. RNA Biol. 14, 1791-1798 https://doi.org/10.1080/15476286.2017.1367888

Kelly DF, Gonzalo IT, Cohan P, Berman N, Swerdloff R, Wang C (2000): Hypopituitarism following traumatic brain injury and aneurysmal subarachnoid hemorrhage: a preliminary report. J. Neurosurg. 93, 743-752 https://doi.org/10.3171/jns.2000.93.5.0743

Kotlyar M, Pastrello C, Malik Z, Jurisica I (2019): IID 2018 update: context-specific physical protein-protein interactions in human, model organisms and domesticated species. Nucleic Acids Res. 47, D581-D589 https://doi.org/10.1093/nar/gky1037

Kowalski EA, Chen J, Hazy A, Fritsch LE, Gudenschwager-Basso EK, Chen M, Wang X, Qian Y, Zhou M, Byerly M et al. (2019): Peripheral loss of EphA4 ameliorates TBI-induced neuroinflammation and tissue damage. J. Neuroinflammation 16, 210 https://doi.org/10.1186/s12974-019-1605-2

Krieg SM, Voigt F, Knuefermann P, Kirschning CJ, Plesnila N, Ringel F (2017): Decreased secondary lesion growth and attenuated immune response after traumatic brain injury in Tlr2/4(-/-) mice. Front. Neurol. 8, 455 https://doi.org/10.3389/fneur.2017.00455

Li Y, Li Y, Li X, Zhang S, Zhao J, Zhu X, Tian G (2017): Head injury as a risk factor for dementia and Alzheimer's disease: A systematic review and meta-analysis of 32 observational studies. PLoS One 12, e0169650 https://doi.org/10.1371/journal.pone.0169650

Lin HJ, Hsu CC, Chio CC, Tian YF, Lin MT, Lin TW, Chang CH, Chang CP (2017): Gamma-secretase inhibitors attenuate neurotrauma and neurogenic acute lung injury in rats by rescuing the accumulation of hypertrophic microglia. Cell Physiol. Biochem. 44, 1726-1740 https://doi.org/10.1159/000485778

Liu-DeRyke X, Collingridge DS, Orme J, Roller D, Zurasky J, Rhoney DH (2009): Clinical impact of early hyperglycemia during acute phase of traumatic brain injury. Neurocrit. Care 11, 151-157 https://doi.org/10.1007/s12028-009-9228-6

Liu DZ, Sharp FR, Van KC, Ander BP, Ghiasvand R, Zhan X, Stamova B, Jickling GC, Lyeth BG (2014a): Inhibition of SRC family kinases protects hippocampal neurons and improves cognitive function after traumatic brain injury. J. Neurotrauma 31, 1268-1276 https://doi.org/10.1089/neu.2013.3250

Liu L, Sun T, Liu Z, Chen X, Zhao L, Qu G, Li Q (2014b): Traumatic brain injury dysregulates microRNAs to modulate cell signaling in rat hippocampus. PLoS One 9, e103948 https://doi.org/10.1371/journal.pone.0103948

Liu W, Liu X, Yang H, Zhu X, Yi H, Zhu X, Zhang J (2013): Phosphorylated retinoblastoma protein $(\mathrm{p}-\mathrm{Rb})$ is involved in neuronal apoptosis after traumatic brain injury in adult rats. J. Mol. Histol. 44, 147-158 https://doi.org/10.1007/s10735-013-9481-z

Long J, Cai L, Li J, Zhang L, Yang H, Wang T (2013): JNK3 involvement in nerve cell apoptosis and neurofunctional recovery after traumatic brain injury. Neural. Regen. Res. 8, 1491-1499 http://dx.doi.org/10.3969/j.issn.1673-5374.2013.16.006

Lu J, Guan F, Cui F, Sun X, Zhao L, Wang Y, Wang X (2019): Enhanced angiogenesis by the hyaluronic acid hydrogels immobilized with a VEGF mimetic peptide in a traumatic brain injury model in rats. Regen. Biomater. 6, 325-334 https://doi.org/10.1093/rb/rbz027

Mangiola A, Vigo V, Anile C, De Bonis P, Marziali G, Lofrese G (2015): Role and Importance of IGF-1 in Traumatic Brain Injuries. Biomed. Res. Int. 2015, 736104 https://doi.org/10.1155/2015/736104

Manley G, Gardner AJ, Schneider KJ, Guskiewicz KM, Bailes J, Cantu RC, Castellani RJ, Turner M, Jordan BD, Randolph C et al. (2017): A systematic review of potential long-term effects of sport-related concussion. Br. J. Sports Med. 51, 969-977 https://doi.org/10.1136/bjsports-2017-097791

Mannix RC, Zhang J, Park J, Lee C, Whalen MJ (2011): Detrimental effect of genetic inhibition of B-site APP-cleaving enzyme 1 on 
functional outcome after controlled cortical impact in young adult mice. J. Neurotrauma 28, 1855-1861

https://doi.org/10.1089/neu.2011.1759

Mao SS, Hua R, Zhao XP, Qin X, Sun ZQ, Zhang Y, Wu YQ, Jia MX, Cao JL, Zhang YM (2012): Exogenous administration of PACAP alleviates traumatic brain injury in rats through a mechanism involving the TLR4/MyD88/NF-kappaB pathway. J. Neurotrauma 29, 1941-1959 https://doi.org/10.1089/neu.2011.2244

Marambaud P, Shioi J, Serban G, Georgakopoulos A, Sarner S, Nagy V, Baki L, Wen P, Efthimiopoulos S, Shao Z et al. (2002): A presenilin-1/gamma-secretase cleavage releases the E-cadherin intracellular domain and regulates disassembly of adherens junctions. EMBO J. 21, 1948-1956 https://doi.org/10.1093/emboj/21.8.1948

Marchetti B, Pluchino S (2013): Wnt your brain be inflamed? Yes, it Wnt! Trends Mol. Med. 19, 144-156 https://doi.org/10.1016/j.molmed.2012.12.001

Martinowich K, Lu B (2008): Interaction between BDNF and serotonin: role in mood disorders. Neuropsychopharmacology 33, 73-83 https://doi.org/10.1038/sj.npp.1301571

McCrea MA, Nelson LD, Guskiewicz K (2017): Diagnosis and management of acute concussion. Phys. Med. Rehabil. Clin. N Am. 28, 271-286 https://doi.org/10.1016/j.pmr.2016.12.005

McCrory P, Johnston K, Meeuwisse W, Aubry M, Cantu R, Dvorak J, Graf-Baumann T, Kelly J, Lovell M, Schamasch P (2005): Summary and agreement statement of the 2nd International Conference on Concussion in Sport, Prague 2004. Br. J. Sports Med. 39, 196-204 https://doi.org/10.1097/01.jsm.0000159931.77191.29

McKee AC, Cantu RC, Nowinski CJ, Hedley-Whyte ET, Gavett BE, Budson AE, Santini VE, Lee HS, Kubilus CA, Stern RA (2009): Chronic traumatic encephalopathy in athletes: progressive tauopathy after repetitive head injury. J. Neuropathol. Exp. Neurol. 68, 709-735 https://doi.org/10.1097/NEN.0b013e3181a9d503

McKee AC, Robinson ME (2014): Military-related traumatic brain injury and neurodegeneration. Alzheimers Dement. 10, S242-253 https://doi.org/10.1016/j.jalz.2014.04.003

Meabon JS, Cook DG, Yagi M, Terry GE, Cross DJ, Muzi M, Pagulayan KF, Logsdon AF, Schindler AG, Ghai V et al. (2020): Chronic elevation of plasma vascular endothelial growth factorA (VEGF-A) is associated with a history of blast exposure. J. Neurol. Sci. 417, 117049 https://doi.org/10.1016/j.jns.2020.117049

Mellergard P, Sjogren F, Hillman J (2010): Release of VEGF and FGF in the extracellular space following severe subarachnoidal haemorrhage or traumatic head injury in humans. Br. J. Neurosurg. 24, 261-267 https://doi.org/10.3109/02688690903521605

Menon DK, Schwab K, Wright DW, Maas AI, Demographics, Clinical Assessment Working Group of the I, Interagency Initiative toward Common Data Elements for Research on Traumatic Brain Injury and Psychological Health (2010): Position statement: definition of traumatic brain injury. Arch. Phys. Med. Rehabil. 91, 1637-1640 https://doi.org/10.1016/j.apmr.2010.05.017

Murayama M, Tanaka S, Palacino J, Murayama O, Honda T, Sun X, Yasutake K, Nihonmatsu N, Wolozin B, Takashima A (1998): Direct association of presenilin-1 with beta-catenin. FEBS Lett. 433, 73-77 https://doi.org/10.1016/S0014-5793(98)00886-2

Nag S, Takahashi JL, Kilty DW (1997): Role of vascular endothelial growth factor in blood-brain barrier breakdown and angiogenesis in brain trauma. J. Neuropathol. Exp. Neurol. 56, $912-921$ https://doi.org/10.1097/00005072-199708000-00009

Newell EA, Todd BP, Mahoney J, Pieper AA, Ferguson PJ, Bassuk AG (2018): Combined blockade of interleukin-1alpha and -1beta signaling protects mice from cognitive dysfunction after traumatic brain injury. eNeuro 5, 1-15 https://doi.org/10.1523/ENEURO.0385-17.2018

Oliva AA, Jr., Kang Y, Sanchez-Molano J, Furones C, Atkins CM (2012): STAT3 signaling after traumatic brain injury. J. Neurochem. 120, 710-720 https://doi.org/10.1111/j.1471-4159.2011.07610.x

Omalu B, Hammers J (2021): Letter: Recommendation to create new neuropathologic guidelines for the post-mortem diagnosis of chronic traumatic encephalopathy. Neurosurgery 89, E97-E98 https://doi.org/10.1093/neuros/nyab138

Omalu BI, DeKosky ST, Minster RL, Kamboh MI, Hamilton RL, Wecht CH (2005): Chronic traumatic encephalopathy in a National Football League player. Neurosurgery 57, 128-134 https://doi.org/10.1227/01.NEU.0000163407.92769.ED

Ou S, Liu GD, Zhou LS, Xia X, Bai SR, Li J, Cui J, Cheng JM, Li YM, Zhang XY et al. (2014): Bioinformatics analysis of gene expression profiles in the rat cerebral cortex following traumatic brain injury. Eur. Rev. Med. Pharmacol. Sci. 18, 101-107

Patel RK, Prasad N, Kuwar R, Haldar D, Abdul-Muneer PM (2017): Transforming growth factor-beta 1 signaling regulates neuroinflammation and apoptosis in mild traumatic brain injury. Brain Behav. Immun. 64, 244-258 https://doi.org/10.1016/j.bbi.2017.04.012

Pinero J, Bravo A, Queralt-Rosinach N, Gutierrez-Sacristan A, DeuPons J, Centeno E, Garcia-Garcia J, Sanz F, Furlong LI (2017): DisGeNET: a comprehensive platform integrating information on human disease-associated genes and variants. Nucleic Acids Res. 45, D833-D839 https://doi.org/10.1093/nar/gkw943

Pinchi E, Frati P, Arcangeli M, Volonnino G, Tomassi R, Santoro P, Cipolloni L (2020): MicroRNAs: The new challenge for traumatic brain injury diagnosis. Curr. Neuropharmacol. 18, 319-331 https://doi.org/10.2174/1570159X17666191113100808

Qin X, Li L, Lv Q, Shu Q, Zhang Y, Wang Y (2018): Expression profile of plasma microRNAs and their roles in diagnosis of mild to severe traumatic brain injury. PLoS One 13, e0204051 https://doi.org/10.1371/journal.pone.0204051

Rahmati S, Abovsky M, Pastrello C, Jurisica I (2017): pathDIP: an annotated resource for known and predicted human genepathway associations and pathway enrichment analysis. Nucleic Acids Res. 45, D419-D426 https://doi.org/10.1093/nar/gkw1082 
Rahmati S, Abovsky M, Pastrello C, Kotlyar M, Lu R, Cumbaa CA, Rahman P, Chandran V, Jurisica I (2020): pathDIP 4: an extended pathway annotations and enrichment analysis resource for human, model organisms and domesticated species. Nucleic Acids Res. 48, D479-D488 https://doi.org/10.1093/nar/gkz989

Redell JB, Moore AN, Ward NH, 3rd, Hergenroeder GW, Dash PK (2010): Human traumatic brain injury alters plasma microRNA levels. J. Neurotrauma 27, 2147-2156 https://doi.org/10.1089/neu.2010.1481

Rubovitch V, Edut S, Sarfstein R, Werner H, Pick CG (2010): The intricate involvement of the Insulin-like growth factor receptor signaling in mild traumatic brain injury in mice. Neurobiol. Dis. 38, 299-303 https://doi.org/10.1016/j.nbd.2010.01.021

Rubovitch V, Shachar A, Werner H, Pick CG (2011): Does IGF-1 administration after a mild traumatic brain injury in mice activate the adaptive arm of ER stress? Neurochem. Int. 58, 443-446 https://doi.org/10.1016/j.neuint.2011.01.009

Salinas PC (2012): Wnt signaling in the vertebrate central nervous system: from axon guidance to synaptic function. Cold Spring Harb. Perspect. Biol. 4, a008003 https://doi.org/10.1101/cshperspect.a008003

Sandhir R, Berman NE (2010): Age-dependent response of CCAAT/enhancer binding proteins following traumatic brain injury in mice. Neurochem. Int. 56, 188-193 https://doi.org/10.1016/j.neuint.2009.10.002

Sarkar C, Jones JW, Hegdekar N, Thayer JA, Kumar A, Faden AI, Kane MA, Lipinski MM (2020): PLA2G4A/cPLA2-mediated lysosomal membrane damage leads to inhibition of autophagy and neurodegeneration after brain trauma. Autophagy 16, 466-485 https://doi.org/10.1080/15548627.2019.1628538

Scranton RA, Baskin DS (2015): Impaired pituitary axes following traumatic brain injury. J. Clin. Med. 4, 1463-1479 https://doi.org/10.3390/jcm4071463

Sheinerman KS, Toledo JB, Tsivinsky VG, Irwin D, Grossman M, Weintraub D, Hurtig HI, Chen-Plotkin A, Wolk DA, McCluskey LF et al. (2017): Circulating brain-enriched microRNAs as novel biomarkers for detection and differentiation of neurodegenerative diseases. Alzheimers Res. Ther. 9, 89 https://doi.org/10.1186/s13195-017-0316-0

Shetty VS, Reis MN, Aulino JM, Berger KL, Broder J, Choudhri AF, Kendi AT, Kessler MM, Kirsch CF, Luttrull MD et al. (2016): ACR appropriateness criteria head trauma. J. Am. Coll. Radiol. 13, 668-679 https://doi.org/10.1016/j.jacr.2016.02.023

Siedlecki-Wullich D, Catala-Solsona J, Fabregas C, Hernandez I, Clarimon J, Lleo A, Boada M, Saura CA, Rodriguez-Alvarez J, Minano-Molina AJ (2019): Altered microRNAs related to synaptic function as potential plasma biomarkers for Alzheimer's disease. Alzheimers Res. Ther. 11, 46 https://doi.org/10.1186/s13195-019-0501-4

Singh K, Trivedi R, Devi MM, Tripathi RP, Khushu S (2016): Longitudinal changes in the DTI measures, anti-GFAP expression and levels of serum inflammatory cytokines following mild traumatic brain injury. Exp. Neurol. 275, 427-435 https://doi.org/10.1016/j.expneurol.2015.07.016
Smith DH, Johnson VE, Stewart W (2013): Chronic neuropathologies of single and repetitive TBI: substrates of dementia? Nat. Rev. Neurol. 9, 211-221

https://doi.org/10.1038/nrneurol.2013.29

Stoica BA, Loane DJ, Zhao Z, Kabadi SV, Hanscom M, Byrnes KR, Faden AI (2014): PARP-1 inhibition attenuates neuronal loss, microglia activation and neurological deficits after traumatic brain injury. J. Neurotrauma 31, 758-772 https://doi.org/10.1089/neu.2013.3194

Sun D, Bullock MR, Altememi N, Zhou Z, Hagood S, Rolfe A, McGinn MJ, Hamm R, Colello RJ (2010): The effect of epidermal growth factor in the injured brain after trauma in rats. J. Neurotrauma 27, 923-938 https://doi.org/10.1089/neu.2009.1209

Sun L, Liu A, Zhang J, Ji W, Li Y, Yang X, Wu Z, Guo J (2018): miR23b improves cognitive impairments in traumatic brain injury by targeting ATG12-mediated neuronal autophagy. Behav. Brain Res. 340, 126-136 https://doi.org/10.1016/j.bbr.2016.09.020

Sun Y, Bai L, Niu X, Wang Z, Yin B, Bai G, Zhang D, Gan S, Sun C, Wang $S$ et al. (2019): Elevated serum levels of inflammationrelated cytokines in mild traumatic brain injury are associated with cognitive performance. Front. Neurol. 10, 1120 https://doi.org/10.3389/fneur.2019.01120

Sun Y, Jin K, Xie L, Childs J, Mao XO, Logvinova A, Greenberg DA (2003): VEGF-induced neuroprotection, neurogenesis, and angiogenesis after focal cerebral ischemia. J. Clin. Invest. 111, 1843-1851 https://doi.org/10.1172/JCI200317977

Tamas A, Zsombok A, Farkas O, Reglodi D, Pal J, Buki A, Lengvari I, Povlishock JT, Doczi T (2006): Postinjury administration of pituitary adenylate cyclase activating polypeptide (PACAP) attenuates traumatically induced axonal injury in rats. J. Neurotrauma $23,686-695$ https://doi.org/10.1089/neu.2006.23.686

Tang C, Shan Y, Hu Y, Fang Z, Tong Y, Chen M, Wei X, Fu X, Xu $X$ (2017): FGF2 attenuates neural cell death via suppressing autophagy after rat mild traumatic brain injury. Stem Cells Int. 2017, 2923182 https://doi.org/10.1155/2017/2923182

Tas D, Kaplan O, Sogut O (2020): Validity of serum miRNA 93 and miRNA 191 to reduce unnecessary computed tomography in patients with mild head trauma. J. Clin. Med. Res. 12, 579-589 https://doi.org/10.14740/jocmr4265

Tate CC, Garcia AJ, LaPlaca MC (2007): Plasma fibronectin is neuroprotective following traumatic brain injury. Exp. Neurol. 207, 13-22 https://doi.org/10.1016/j.expneurol.2007.05.008

Teasdale G, Jennett B (1976): Assessment and prognosis of coma after head injury. Acta Neurochir. (Wien). 34, 45-55 https://doi.org/10.1007/BF01405862

Terzioglu B, Ekinci O, Berkman Z (2015): Hyperglycemia is a predictor of prognosis in traumatic brain injury: Tertiary intensive care unit study. J. Res. Med. Sci. 20, 1166-1171 https://doi.org/10.4103/1735-1995.172984

Thau-Zuchman O, Shohami E, Alexandrovich AG, Leker RR (2010): Vascular endothelial growth factor increases neurogenesis 
after traumatic brain injury. J. Cereb. Blood Flow Metab. 30, $1008-1016$

https://doi.org/10.1038/jcbfm.2009.271

Tokar T, Pastrello C, Rossos AEM, Abovsky M, Hauschild AC, Tsay M, Lu R, Jurisica I (2018): mirDIP 4.1-integrative database of human microRNA target predictions. Nucleic Acids Res. 46, D360-D370

https://doi.org/10.1093/nar/gkx1144

Truettner JS, Hu B, Alonso OF, Bramlett HM, Kokame K, Dietrich WD (2007): Subcellular stress response after traumatic brain injury. J. Neurotrauma 24, 599-612 https://doi.org/10.1089/neu.2006.0186

Tylicka M, Matuszczak E, Hermanowicz A, Debek W, Karpinska M, Kaminska J, Koper-Lenkiewicz OM (2020): BDNF and IL-8, but not UCHL-1 and IL-11, are markers of brain injury in children caused by mild head trauma. Brain Sci. 10, 665 https://doi.org/10.3390/brainsci10100665

Uwatoko H, Hama Y, Iwata IT, Shirai S, Matsushima M, Yabe I, Utsumi J, Sasaki H (2019): Identification of plasma microRNA expression changes in multiple system atrophy and Parkinson's disease. Mol. Brain 12, 49 https://doi.org/10.1186/s13041-019-0471-2

Ved R, Sharouf F, Harari B, Muzaffar M, Manivannan S, Ormonde C, Gray WP, Zaben M (2021): Disulfide HMGB1 acts via TLR2/4 receptors to reduce the numbers of oligodendrocyte progenitor cells after traumatic injury in vitro. Sci. Rep. 11, 6181 https://doi.org/10.1038/s41598-021-84932-0

Wang Y, Hameed MQ, Rakhade SN, Iglesias AH, Muller PA, Mou DL, Rotenberg A (2014): Hippocampal immediate early gene transcription in the rat fluid percussion traumatic brain injury model. Neuroreport 25, 954-959 https://doi.org/10.1097/WNR.0000000000000219

Weisz HA, Kennedy D, Widen S, Spratt H, Sell SL, Bailey C, Sheffield-Moore M, DeWitt DS, Prough DS, Levin H et al. (2020): MicroRNA sequencing of rat hippocampus and human biofluids identifies acute, chronic, focal and diffuse traumatic brain injuries. Sci. Rep. 10, 3341

https://doi.org/10.1038/s41598-020-60133-z

Wintermark M, Sanelli PC, Anzai Y, Tsiouris AJ, Whitlow CT, Institute ACRHI, Institute ACRHI (2015): Imaging evidence and recommendations for traumatic brain injury: conventional neuroimaging techniques. J. Am. Coll. Radiol. 12, e1-14 https://doi.org/10.1016/j.jacr.2014.10.014

Wu J, Vogel T, Gao X, Lin B, Kulwin C, Chen J (2018): Neuroprotective effect of dexmedetomidine in a murine model of traumatic brain injury. Sci. Rep. 8, 4935

https://doi.org/10.1038/s41598-018-23003-3

Yan J, Bu X, Li Z, Wu J, Wang C, Li D, Song J, Wang J (2019): Screening the expression of several miRNAs from TaqMan Low Density Array in traumatic brain injury: miR-219a-5p regulates neuronal apoptosis by modulating CCNA2 and CACUL1. J. Neurochem. 150, 202-217 https://doi.org/10.1111/jnc. 14717

Yang J, You Z, Kim HH, Hwang SK, Khuman J, Guo S, Lo EH, Whalen $M J$ (2010): Genetic analysis of the role of tumor necrosis factor receptors in functional outcome after traumatic brain injury in mice. J. Neurotrauma 27, 1037-1046 https://doi.org/10.1089/neu.2009.1229

Yang L, Wu H, Yang F, Li P, Huang Y, Zhang X, Qian C (2021): Identification of candidate genes and pathways in dexmedetomidine-induced neuroprotection in rats using RNA sequencing and bioinformatics analysis. Ann. Palliat. Med. 10, 372-384 https://doi.org/10.21037/apm-20-2346

Yang T, Song J, Bu X, Wang C, Wu J, Cai J, Wan S, Fan C, Zhang C, Wang J (2016): Elevated serum miR-93, miR-191, and miR-499 are noninvasive biomarkers for the presence and progression of traumatic brain injury. J. Neurochem. 137, 122-129 https://doi.org/10.1111/jnc.13534

Yao XL, Liu J, Lee E, Ling GS, McCabe JT (2006): Cullin 5 gene expression in the rat cerebral cortex and hippocampus following traumatic brain injury (TBI). Neurosci. Lett. 409, 65-69 https://doi.org/10.1016/j.neulet.2006.09.015

Yoshino A, Hovda DA, Kawamata T, Katayama Y, Becker DP (1991): Dynamic changes in local cerebral glucose utilization following cerebral conclusion in rats: evidence of a hyper- and subsequent hypometabolic state. Brain Res. 561, 106-119 https://doi.org/10.1016/0006-8993(91)90755-K

Zhang JY, Lee JH, Gu X, Wei ZZ, Harris MJ, Yu SP, Wei L (2018): Intranasally delivered Wnt 3 a improves functional recovery after traumatic brain injury by modulating autophagic, apoptotic, and regenerative pathways in the mouse brain. J. Neurotrauma $35,802-813$ https://doi.org/10.1089/neu.2016.4871

Zhao J, Xu C, Cao H, Zhang L, Wang X, Chen S (2019): Identification of target genes in neuroinflammation and neurodegeneration after traumatic brain injury in rats. PeerJ. 7, e8324 https://doi.org/10.7717/peerj.8324

Zhao Y, Gibb SL, Zhao J, Moore AN, Hylin MJ, Menge T, Xue H, Baimukanova G, Potter D, Johnson EM et al. (2016): Wnt3a, aprotein secreted by mesenchymal stem cells is neuroprotective and promotes neurocognitive recovery following traumatic brain injury. Stem Cells 34, 1263-1272 https://doi.org/10.1002/stem.2310

Zimering MB, Patel D, Bahn G (2019): Type 2 diabetes predicts increased risk of neurodegenerative complications in veterans suffering traumatic brain injury. J. Endocrinol. Diabetes 6, 137 https://doi.org/10.15226/2374-6890/6/3/001137

Received: July 23, 2021

Final version accepted: September 20, 2021 


\title{
Supplementary Material
}

\section{Peripheral microRNA alteration and pathway signaling after mild traumatic brain injury}

\author{
Katarina Matyasova $^{1, *}$, Nikoleta Csicsatkova $^{1, \star}$, Peter Filipcik ${ }^{1,2}$, Igor Jurisica ${ }^{1,3,4,5}$ \\ and Martin Cente ${ }^{1,2} \mathbb{B}$ \\ ${ }^{1}$ Institute of Neuroimmunology, Slovak Academy of Sciences, Bratislava, Slovakia \\ ${ }^{2}$ Axon Neuroscience R\&D Services SE, Bratislava, Slovakia \\ ${ }^{3}$ Osteoarthritis Research Program, Division of Orthopedic Surgery, Schroeder Arthritis Institute, University Health Network, \\ Toronto, Ontario, Canada \\ ${ }^{4}$ Data Science Discovery Centre for Chronic Diseases, Krembil Research Institute, University Health Network, Toronto, \\ Ontario, Canada \\ ${ }^{5}$ Departments of Medical Biophysics and Computer Science, University of Toronto, Toronto, Ontario, Canada
}

Supplement 1. Dysregulated miRNAs in serum, plasma and saliva after mild TBI.

Supplement 2. miRNA to unique target gene prediction based on mirDIP version 4.1.11.1 (database version 4.1.0.3): microRNA Data Integration Portal (http://ophid.utoronto.ca/mirDIP).

Supplement 3. Pathway enrichment analysis-pathDIP version 4.0.21.2 (database version 4.0.7.0): Annotated database of signaling cascades (http://ophid.utoronto.ca/pathDIP/).

Supplement 4. Protein-protein interactions retrieved by Integrated Interactions Database (IID), version 2018-11 (http://ophid.utoronto. ca/iid).

Supplementary files are available on: www.gpb.sav.sk/2021/Matyasova_et_al_4021.pdf 